\title{
Museos accesibles para todos. Diagnóstico de la accesibilidad universal de los museos de Caen (Francia)
}

\author{
Museums accessible to everyone. Diagnosis of the universal accessibility of the Caen \\ museums (France)
}

\author{
Manuel Javier Martínez Carrillo ${ }^{1}$
}

\section{Resumen}

La importancia del turismo cultural dentro de la industria turística europea y el protagonismo de la visita a los museos como una de las actividades más populares, ha impulsado el estudio sobre la accesibilidad universal de los museos. En este estudio de caso se realiza un extenso trabajo de campo se ha basado en la evaluación del grado de accesibilidad de los museos de Caen y sus exposiciones museográficas. Los resultados muestran que los museos Le Mémorial, Musée de Normandie y el Musée de Beaux Arts de Caen (Francia), no son plenamente accesibles universalmente a todas y para todas las personas con discapacidad.

\section{Palabras clave:}

Turismo, Discapacidad, Accesibilidad, Museo, Caen.

\begin{abstract}
The importance of cultural tourism within the European touristic industry and the importance of visiting museums as some of the most popular activities, has encouraged the study of the universal accessibility to museums. For this, our field work has been based on the evaluation of the degree of accessibility of the museums at Caen and its museographic exhibitions. The results show that the museums of Le Mémorial, Musée de Normandie and the Musée de Beaux Arts de Caen (France), are not fully universally accessible to all and for all people with disabilities.
\end{abstract}

Key words:

Tourism, Disability, Accessibility, Museum, Caen.

\footnotetext{
${ }^{1}$ Departamento de Construcciones Arquitectónicas. E.T.S.I.E. Universidad de Granada. Departamento de Instalaciones y Obras. Consejería de Turismo, Justicia, Regeneración y Administración Local. Junta de Andalucía. Granada. Email: manueljmartinez@ugr.es. Orcid Id.: 0000-0001-8570-9489.
} 


\section{Introducción.}

\subsection{Contexto general.}

La Organización Mundial del Turismo (OMT), organismo especializado de las Naciones Unidas encargado de la promoción del desarrollo del turismo responsable, sostenible y universalmente accesible para todos, define al turismo como el conjunto de actividades de las personas que viajan y se alojan en lugares ajenos a su entorno habitual durante un periodo inferior a un año y mayor a un día, por motivos de ocio, negocios u otros.

A nivel mundial, las llegadas de turistas internacionales crecieron un 4,0\% en el año 2019, registrándose un total de mil cuatrocientos sesenta y un millones de llegadas de turistas internacionales en destinos de todo el mundo, en torno a sesenta millones más $(3,8 \%)$ que en $2018^{2}$. Según datos de la OMT, Europa es el principal destino turístico del mundo, con más de la mitad $(50,8 \%)$ de llegadas internacionales. En 2019, el turismo internacional en Europa creció un 3,7\%, alcanzando un total de setecientos cuarenta y dos millones de turistas. Francia ha sido el primer país por número de llegadas turísticas en 2019, alcanzando los ochenta y nueve millones de turistas internacionales, experimentando el mayor crecimiento del gasto en turismo internacional $(11 \%)^{3}$.

El turismo es un importante motor económico que produce el $10 \%$ del producto interior bruto (PIB) mundial y un importante generador de empleo, 1 de cada 10 puestos de trabajo en el mundo, en este sentido, Zurab Pololikashvili, Secretario General de la OMT (2018), subraya que el turismo no solo necesita consolidar sus actuales tasas de crecimiento, sino también crecer mejor, en este sentido, el crecimiento sostenido del turismo ofrece inmensas oportunidades de bienestar económico y desarrollo advirtiendo a la vez que plantea muchos desafios ${ }^{4}$.

La OMT tiene el compromiso de garantizar que el turismo desempeñe un papel clave en la agenda para el desarrollo y en la implementación de los Objetivos de Desarrollo Sostenible $(\mathrm{ODS})^{5}$. En este sentido, las directrices para el desarrollo sostenible del turismo y las prácticas de gestión sostenible deben aplicarse a todas las formas de turismo y en todos los tipos de destinos. La propia OMT define el turismo sostenible como aquel que tiene plenamente en cuenta las repercusiones actuales y futuras, económicas, sociales y medioambientales para satisfacer las necesidades de los visitantes, de la industria, del entorno y de las comunidades anfitrionas. Los principios de sostenibilidad se refieren a los aspectos medioambiental, económico y sociocultural del desarrollo turístico, debiéndose conseguir un equilibrio adecuado entre estas tres dimensiones para garantizar su sostenibilidad a largo plazo.

\subsection{Turismo cultural.}

Según la OMT, el 40\% de las llegadas internacionales son consideradas turistas culturales. Aún cuando existen diferentes definiciones sobre turismo cultural, la OMT(1995) establece como turismo cultural todos los movimientos de las personas para satisfacer la

\footnotetext{
2 Barómetro OMT del Turismo Mundial Edición 2019.

${ }^{3}$ Barómetro OMT del Turismo Mundial Edición 2019.

${ }^{4}$ Discurso inaugural de Feria de Turismo de Berlín. ITB 2018.

${ }^{5}$ Disponible en :https://www.un.org/sustainabledevelopment/es/
} 
necesidad humana de diversidad, orientados a elevar el nivel cultural del individuo, facilitando nuevos conocimientos, experiencias y encuentros, conceptualizando incluso los movimientos de las personas por motivaciones esencialmente culturales como los viajes de estudio, los viajes por motivos de índole artística, tales como diferentes festivales de artes escénicas: el teatro, el cine, la música y otros eventos culturales, así como las visitas a los sitios y monumentos del patrimonio mundial.

La Carta de Turismo Cultural ${ }^{6}$ del Consejo Internacional de Monumentos y Sitios (ICOMOS) (1999), amplía estas definiciones incorporando el concepto de intercambio cultural como una forma turística que ofrece una experiencia personal, no sólo acerca de lo que pervive del pasado, sino de la vida actual y de otras sociedades. Sin embargo, el cambio principal establecido con la Carta de $1976^{7}$ es la relación entre turismo y conservación. En la primera, los turistas eran vistos como una amenaza para la integridad del lugar visitado, y por consiguiente, para el patrimonio. La Carta (ICOMOS) de 1999 señala como una de las principales causas de la conservación, la posibilidad de que el lugar, monumento u objeto sea accesible a todos visitantes, aunque de una manera controlada, ya que sin el propio conocimiento de la importancia que ciertos lugares y monumentos tienen como patrimonio cultural se dificultaría la obtención de los recursos necesarios para su preservación.

La globalización, protección, conservación e interpretación de la diversidad cultural y del patrimonio cultural de cualquier lugar es un importante desafío para nuestra sociedad. En este sentido, partiendo de los principios básicos de la sostenibilidad, la Carta (ICOMOS) de 1999, recomienda minimizar los impactos negativos tanto para el patrimonio como para la comunidad anfitriona, y al mismo tiempo satisfacer la calidad de la experiencia del turista.

La cultura, factor de atracción y factor de riqueza, atrae a los turistas franceses y extranjeros y contribuye en un 2,2\% al producto interno bruto. El $60 \%$ de los turistas internacionales que visitaron Francia en 2019, visito algún espacio cultural y el 10\% participó en algún evento cultural. Francia cuenta con 1.218 museos de Francia (78 en la región de la Normandie) y una cuarentena de museos nacionales, 51 centros de arte y 23 fondos regionales de arte contemporáneo. En el año 2016 se registraron un total de 59,7 millones de visitas, de las cuales el $63 \%$ fueron a museos de arte, el $18 \%$ a museos de historia, el $10 \%$ a museos de civilización y el $8 \%$ a museos de naturaleza, ciencia y tecnología ${ }^{8}$.

El turismo cultural contribuye al desarrollo cultural, al crecimiento económico y a la revitalización de nuestras ciudades. No olvidando que la cultura es un bien universal y como tal, debe ser accesible a todas las personas.

\subsection{Turismo accesible.}

El Informe mundial sobre discapacidad ${ }^{9}$ de la Organización Mundial de la Salud (OMS) de 2011, estima que más de mil millones de personas (alrededor del 15\% de la población

\footnotetext{
${ }^{6}$ Carta Internacional sobre Turismo Cultural: La gestión del turismo en los sitios con patrimonio significativo. Aprobada por la XII Asamblea General en Guadalajara, México el 22 de octubre de 1999.

${ }^{7}$ Carta Internacional sobre Turismo Cultural, Adoptada por ICOMOS el 16 de noviembre de 1976.

${ }^{8}$ Mémento du tourisme, édition 2018, ministère de l'Économie et des finances, Direction générale des entreprises (dge).

Disponible en https://www.entreprises.gouv.fr/etudes-et-statistiques/memento-du-tourisme-edition-2018

${ }^{9}$ Disponible en http://www.who.int/disabilities/world_report/2011/summary_es.pdf?ua=1
} 
mundial) viven con algún tipo de discapacidad, es decir una de cada siete de la población mundial. Alrededor de ochenta millones de personas en la Unión Europea (UE), tienen alguna discapacidad, enfrentándose a barreras relacionadas con las actitudes y el entorno que impiden su plena participación social y económica. En Francia y de acuerdo con el Instituto Nacional de Estadística y Estudios Económicos (INSEE) cuatro millones seiscientos mil franceses ${ }^{10} \mathrm{se}$ encuentran en situación de discapacidad.

La Convención sobre los Derechos de las Personas con Discapacidad (CDPD), aprobada por la Asamblea General de las Naciones Unidas el 13 de diciembre de $2006^{11}$, ratificada por Francia el 23 de septiembre de 2008, en su artículo 1, define el concepto de discapacidad como, una situación que surge cuando una persona con deficiencias (físicas, sensoriales, cognitivas) temporales o permanentes trata de realizar una actividad, o participar interactuar con el entorno, y se encuentra con limitaciones o restricciones debido a factores sociales (actitudes negativas de otras personas) y ambientales (barreras en el entorno físico y/o tecnológico), por lo cual se evita su participación plena y efectiva en la sociedad, en igualdad de condiciones con las demás.

El 27 de septiembre de 1980, en Manila (Filipinas), se asocia por primera vez los términos turismo y accesibilidad mediante la Declaración de Manila, realizada por la $\mathrm{OMT}^{12}$. Esta declaración ya reconocía el turismo como un derecho fundamental y vehículo clave para el desarrollo humano y recomendaba a los estados miembros la reglamentación de los servicios turísticos, marcando los aspectos más importantes sobre accesibilidad turística, reconociendo el turismo como un derecho fundamental y elemento clave para el desarrollo humano.

Ya en 1999 el Código Ético Mundial para el Turismo aprobado por la Asamblea General de la $\mathrm{OMT}^{13}$, hacía referencia a la promoción de los derechos de las personas con discapacidad para la realización de actividades turísticas, estableciendo en su artículo 2.2 el turismo accesible I turismo para todos, como un derecho ante la discapacidad, las actividades turísticas respetarán la igualdad de hombres y mujeres. Asimismo, se encaminarán a promover los derechos humanos y, en particular, los derechos específicos de los grupos de población más vulnerables, especialmente los niños, las personas mayores y minusválidas, las minorías étnicas y los pueblos autóctonos. Promoviendo en su artículo 7.4 el fomento del turismo de personas discapacitadas, se fomentará y se facilitará el turismo de las familias, de los jóvenes y de los estudiantes, de las personas mayores y de las que padecen minusvalías.

Las visiones estereotipadas de la discapacidad se centran en los usuarios de silla de ruedas y en algunos otros grupos como las personas ciegas o sordas. Las personas con discapacidad no son sólo aquellas que utilizan sillas de ruedas, leen sistemas Braille, utilizan lengua de signos, la comunicación táctil o equipos y aparatos para comunicarse, existen personas cuyas discapacidades no son tan visibles. En este sentido, el INSEE apunta que el 80\% de las personas en situación de discapacidad sufren una discapacidad invisible ${ }^{14}$.

El turismo accesible para todos en aplicación de los criterios de accesibilidad

\footnotetext{
${ }^{10}$ Enquête Handicap-Santé 2008-2009 INSEE.

${ }^{11}$ Disponible en https://www.who.int/disabilities/media/news/unconvention/es/

12 Disponible en https://www.e-unwto.org/doi/pdf/10.18111/unwtodeclarations.1980.6.6.1

${ }^{13}$ Disponible en http://ethics.unwto.org/es/content/codigo-etico-mundial-para-el-turismo

${ }^{14}$ Enquête Handicap-santé - volet ménages (HSM)-2008.
} 
universal $^{15}$, no se limita a la eliminación de barreras físicas, sensoriales, de transporte, de la comunicación o incluso electrónicas, sino que tiene por finalidad lograr que los entornos, productos y servicios turísticos diseñados bajo el principio de diseño universal o diseño para todos, puedan ser usados y disfrutados en igualdad de condiciones por cualquier persona con o sin discapacidad. El turismo accesible beneficia a todos, no solo a las personas con discapacidad y con necesidades especiales, sino a todas las personas, a la vez que abre importantes oportunidades económicas para todos los sectores económicos.

Como esgrimían las Recomendaciones de la OMT por un Turismo Accesible para $\operatorname{Todos}^{16}$, la accesibilidad como aspecto social de la sostenibilidad, es un elemento crucial de toda política de turismo responsable y sostenible. Es una cuestión de derechos humanos y es también una extraordinaria oportunidad de negocio. La Comisión Europea ha demostrado ${ }^{17}$, que el volumen de mercado del turismo accesible en Europa asciende a más de 780 millones de viajes al año, incluyendo los viajes nacionales e intracomunitarios. El estudio también confirmó que la discapacidad no impide que las personas viajen. De hecho, más de la mitad de las personas con discapacidad de la UE viajó durante los 12 meses entre mediados de 2012 y mediados de 2013.

El Comité Mundial de Ética de Turismo considera el turismo accesible como un elemento integrador en el que cualquier producto turístico debería diseñarse de modo que se tuviera en cuenta a todas las personas, independientemente de su edad, sexo o condición, y sin que conllevara costos adicionales para los clientes con discapacidad y necesidades de acceso específicas.

La accesibilidad en el turismo debe plantearse en el desarrollo de todo el ciclo de actividades denominado cadena de valor del turismo accesible, que relaciona diferentes procesos esenciales para completar la experiencia turística. A lo largo de los diferentes eslabones de la cadena de accesibilidad turística nos podemos encontrar con importantes obstáculos, por un lado, barreras físicas en el entorno y por otro barreras sociales. Las primeras, se relacionan con las infraestructuras y entornos construidos, incluyendo la información y la tecnología incluso. Las segundas, se refieren a la formación del personal de las empresas turísticas, falta de concienciación y sensibilización sobre la accesibilidad, los prejuicios e incluso la discriminación de los turistas en situación de discapacidad.

La rotura de un eslabón de la cadena puede dificultar, incluso imposibilitar, el acceso, uso y disfrute de las infraestructuras y servicios turísticos. En este sentido, la falta de información independiente, objetiva y veraz en materia de accesibilidad, implica un mayor riesgo para el turista con discapacidad. En esta sociedad de la información, los datos sobre las condiciones reales de accesibilidad, son escasos y en muchas ocasiones no se corresponden con la realidad.

\subsection{Museos accesibles para todos.}

\footnotetext{
${ }^{15}$ Accesibilidad a todo y para todos, es la condición que deben cumplir los entornos, procesos, bienes, productos y servicios, así como los objetos o instrumentos, herramientas y dispositivos, para ser comprensibles, utilizables y practicables por todas las personas en condiciones de seguridad y comodidad y de la forma más autónoma y natural posible. Presupone la estrategia de diseño universal o diseño para todas las personas, y se entiende sin perjuicio de los ajustes razonables que deban adoptarse. Definición dada por la Convención Internacional de los Derechos de las personas con discapacidad.

${ }^{16}$ Adoptadas por la Resolución A/RES/637(XX) de la Asamblea General de la OMT en agosto de 2013.

${ }^{17}$ Economic impact and travel patterns of Accesible Tourism in Europe - Final Report- European Commission, DG Enterprise and Industry.
} 
Legalmente, un museo es cualquier colección permanente compuesta de objetos cuya conservación y presentación son de interés público y están organizados con fines de conocimiento, educación y disfrute públicos. La denominación Musées de France se regula en la Ley $\mathrm{n}^{\mathrm{o}}$ 2002-5, de 4 de enero de 2002, modificada por la Ordenanza 2004-178 de 20 de febrero de $2004^{18}$, y puede concederse a los museos de propiedad del Estado francés, a otra persona jurídica de derecho público o a una persona jurídica sin ánimo de lucro de derecho privado. Los museos en Francia incluyen los museos nacionales, los museos estatales, cuyo estatuto se determina por decreto, los museos clasificados de acuerdo con las leyes y reglamentos vigentes antes de la nueva ley y los museos controlados anteriormente por el Ministro de Cultura o el Ministro de Investigación ${ }^{19}$.

Los museos son los centros de atracción turística mas representativos dentro del ámbito del turismo cultural, como bien universal que son, deben estar al alcance de todas las personas sin ningún tipo de barreras en la prestación de sus servicios. No obstante la realidad, es que no todas las personas tienen las mismas oportunidades de acceder a ellos y disfrutar de sus colecciones.

Los museos accesibles eliminan las barreras físicas, sensoriales e intelectuales/cognitivas para garantizar una óptima accesibilidad, tanto a sus instalaciones como a sus contenidos. El museo accesible no tiene barreras, ofrece actividades específicas y acerca la cultura a las personas con necesidades especiales para mejorar su calidad de vida y facilitar su integración en la sociedad. No obstante, la adaptación de museos clásicos o históricos en edificios monumentales es costosa y técnicamente difícil de conseguir. Instalar rampas, barandillas, ascensores, plataformas elevadoras, señalar los suelos, las escaleras, adaptar los aseos y transformar vitrinas, luces, rótulos y programas audiovisuales o informáticos no solo es tarea ardua, sino que a menudo se encuentra con el rechazo de algunos conservadores que temen que se alteren los recorridos históricos o conceptuales del propio museo. No obstante, la colaboración interdisciplinar entre la museología y otros profesionales, imprescindible para el desarrollo de los planes de accesibilidad, contribuirá a la implementación de la accesibilidad universal en los museos.

Implementar la accesibilidad en los museos significa cubrir las necesidades de sus visitantes. Permitir a una persona ciega que los contenidos lleguen a través de la percepción de otros sentidos como el tacto y la audición, permitir a una persona sorda una comunicación interactiva a través de lengua de signos o subtitular los sonidos de un video, permitir a una persona con movilidad reducida poder desplazarse con total autonomía y seguridad eliminando las barreras físicas de su entorno, diseñar una visita en lenguaje fácil para niños con Síndrome de Down, etc.

Aplicada al contexto del acceso al arte y la cultura, la accesibilidad universal museológica es la cualidad que describe el grado en que cualquier persona es capaz de acceder tanto al entorno físico, como a los contenidos de un museo, independientemente de su situación

\footnotetext{
${ }^{18}$ Disponible en: https://www.legifrance.gouv.fr/affichTexte.do?cidTexte=JORFTEXT000000769536\&dateTexte=20200318

${ }^{19}$ Ministère de la Culture, Direction générale des patrimoines (mcc/dgp), Service des musées de France et Département de la politique des publics-http://www.culturecommunication.gouv.fr/Politiques-ministerielles/Connaissance-des-patrimoines-et-de-l-architecture/Departementde-la-politique-des-publics
} 
o discapacidad. La accesibilidad universal y la formación del personal de museo para atender las demandas de todo el público, incluido el público en situación de discapacidad, así como la organización de eventos y actividades que integren a todas las personas, han de ser condiciones indispensables de un museo sostenible, accesible y responsable.

Sin duda, implementar la accesibilidad universal en un museo supone una inversión a corto, mediano o largo plazo, dependiendo de la intervención que se requiera, pero no se debe considerar como inversión económica, se trata de una verdadera inversión social y cultural. Un museo diseñado para todos, que ha considerado los criterios del diseño universal, permite el acercamiento a la cultura a una diversidad de personas con diferentes necesidades, y eso redundará en beneficios sociales y económicos, es decir, mayor numero de visitantes, mayor interés turístico, aumento de los ingresos, mejora de la imagen institucional y responsabilidad social y corporativa. Un museo accesible será un museo sostenible y un museo sostenible será un museo inclusivo y responsable.

\section{2.. Objetivos y metodología.}

\subsection{Objetivos.}

El objetivo general de este estudio ha sido conocer el grado de accesibilidad universal y adaptación a las personas con discapacidad tanto física como sensorial, de los museos de Caen (Francia). En concreto se han estudiado y analizado los siguientes museos:

- Le Mémorial.

- Musée de Normandie.

- Musée des Beaux Arts de Caen.

Se pretende analizar un criterio complejo, como es la accesibilidad universal tanto espacial como patrimonial para visitantes en situación de discapacidad. La metodología propuesta define un grado de accesibilidad global para cada museo, resultado del análisis de los espacios visitables del mismo desde su importancia artístico-patrimonial y su accesibilidad universal, física, sensorial y cognitiva.

\subsection{Metodología, indicadores utilizados y planteamiento del estudio.}

Para alcanzar el objetivo propuesto se han utilizado diferentes métodos de análisis y estudio. La metodología parte, en primer lugar, de la recopilación de la legislación vigente relacionada con la accesibilidad y la igualdad de derechos y no discriminación de las personas en situación de discapacidad tanto a nivel internacional como en el ámbito francés. En segundo lugar se han analizado las diferentes normas ISO (International Organization for Standardization) desarrolladas tanto por el comité técnico ISO/TC 228, Tourism and related services como por el comité ISO/TC 59 Buildings and civil engineering works, que establecen directrices y prácticas que promueven la accesibilidad universal tanto en el turismo como en el entorno construido. Conocer el nivel de accesibilidad requiere analizar tanto las dimensiones espaciales, necesarias para desplazarse o utilizar las instalaciones, como las dimensiones sensoriales o cognitivas, precisas para comunicarse o recibir información, constituyendo la dimensión objetiva de la accesibilidad. Para ello se han estudiado una serie de indicadores en cuanto a la accesibilidad universal (tabla 1), siguiendo las determinaciones de la Norma Internacional ISO 21542:2011 Building construction - Accessibility and usability of the built 
environment, que permiten recoger tanto información general como específica de los diferentes elementos que componen los eslabones de la cadena de accesibilidad en las infraestructuras museísticas de Caen, y poder así realizar la correspondiente auditoría de accesibilidad.

A partir de estos indicadores generales (Tabla 1) se ha desarrollado una serie de subindicadores que se concreta en parámetros objetivables y medibles, como la anchura de las puertas y de los pasillos, la instalación de pavimentos podo táctiles integrados en un sistema de encaminamientos para conducir a puntos concretos de interés a las personas que presentan problemas de visión o de comprensión del entorno así como de advertencia de la presencia de escaleras, la dotación de ascensores accesibles con botoneras interiores y exteriores adaptadas, existencia de bucles magnéticos en puntos de atención al turista destinados a mejorar la comunicación con aquéllos con dificultades auditivas, existencia de apoyos isquiáticos, mostradores a doble altura y aseos adaptados para personas usuarias de silla de ruedas, sistema de señalización integral de todos los espacios con diferentes formatos visual-táctil, condiciones de visibilidad con alto contraste figura-fondo y tamaño adecuado de caracteres e incorporación de pictogramas adaptados, normalizados y de fácil comprensión que permitan el uso, la orientación y el reconocimiento de las distintas zonas y elementos de mobiliario presentes en las infraestructuras y sobre todo que faciliten su evacuación del museo en condiciones de seguridad.

\section{Tabla 1. Indicadores de accesibilidad general utilizados}

1.- Cómo llegar al museo.

- Al museo se debe acceder a través de un itinerario accesible, espacio público destinado al tránsito de cualquier peatón o al tránsito mixto de peatones y vehículos.

- El itinerario peatonal debe ser accesible desde las paradas de autobús, y estacionamientos o aparcamientos reservados a personas con discapacidad.

- Se deberán dotar de una señalización apropiada sobre la organización del área, horarios, actividades, etc. Para ello, los paneles informativos y planos guía deberán contemplar los requisitos de accesibilidad.

2. Plazas de aparcamiento reservadas.

Los aparcamientos de uso público que estén al servicio o cerca del museo deben disponer de plazas de aparcamiento reservadas para personas con movilidad reducida, con las siguientes características:

- Estar debidamente señalizadas horizontal y verticalmente con el Símbolo Internacional de Accesibilidad (SIA).

- Situarse lo más cerca posible a los accesos peatonales.

- Tener las dimensiones mínimas establecidas (2,20 x 5 m y zona de aproximación y transferencia de 1,50 m).

- Estar conectados con la entrada principal del museo por un itinerario peatonal accesible.

3.- Entrada al museo.

- El acceso principal al interior del museo debe realizarse sin diferencia de nivel o, en caso de que exista, con una rampa accesible con espacio mínimo de giro de 1,50 m., vinculado a un espacio o a un itinerario peatonal accesible.

- No habrá ningún tipo de obstáculo, y si existe puerta deberá ser abatible o corredera. Si son de vidrio, estarán señalizadas con marcas de color contrastado a doble altura que faciliten su detección a personas con visión reducida. El ancho útil de paso de la puerta será al menos de $0,80 \mathrm{~m}$.

- En el resto de entradas existirá señalización que indique la existencia y ubicación del acceso adaptado.

- Tanto la señalización como las entradas estarán bien iluminadas.

- Existirán puntos de atención accesible y puntos de llamada accesible, dotados de bucle magnético para atender a visitantes con discapacidad auditiva.

- Si la entrada principal del museo no es accesible, debe habilitarse otra entrada alternativa accesible, con la misma importancia que la principal y fácilmente identificable desde la vía pública.

4.- Comunicación horizontal.

- En los diferentes itinerarios del museo hay que prestar atención al tipo de pavimento, a la pendiente del suelo, a los desniveles, a las puertas de paso y a la anchura y altura libre en pasillos.

- El pavimento debe ser antideslizante tanto seco como húmedo. El suelo debe ser siempre horizontal en todo el recorrido. En caso de existir desniveles (escalones aislados, etc.) se salvarán por medio de rampa o productos de apoyo. 
- El borde de los escalones aislados debe señalizarse con una franja de pavimento táctil señalizador de color contrastado. - A cada lado de las puertas de paso debe existir un rellano horizontal con un espacio libre de al menos 1,50 m de diámetro. Su sistema de apertura será preferiblemente automático o fácil de manipular.

- Las puertas y mamparas de vidrio contarán con marcas de color contrastado a doble altura para que puedan ser detectadas por personas de visión reducida.

- El ancho de los pasillos debe ser de al menos 1,50 $\mathrm{m}$ y preferiblemente de $2 \mathrm{~m}$.

- La altura libre de paso de los pasillos será de un mínimo de $2,10 \mathrm{~m}$.

- No existirá mobiliario u objeto que no pueda detectarse con el bastón guía, tales como elementos salientes de más de $15 \mathrm{~cm}$ de fondo que no arranquen desde el suelo y estén situados a una altura inferior a $2,20 \mathrm{~m}$.

- Se utilizará el contraste cromático entre paredes, suelos y puertas para facilitar la orientación de personas con visión reducida o discapacidad cognitiva.

5.- Comunicación vertical.

- Las escaleras serán de directriz recta, en curva o en espiral no son recomendables. Deben contar con pasamanos en ambos lados.

- Debe existir un contraste visual entre las mesetas y los escalones superior e inferior de cada tramo de escalera, así como contar con pavimento táctil indicador de advertencia al inicio y final de las escaleras.

- La anchura mínima de un tramo de escaleras debe ser de 1,20 m.

- Las huellas y contrahuellas de los peldaños deben ser uniformes a lo largo de los tramos. La contrahuella de los escalones no debería ser superior a $0,15 \mathrm{~m}$ y la huella no debería ser inferior a $0,30 \mathrm{~m}$.

- El ascensor debe cumplir la norma UNE-EN 81-70:2004 relativa a la "Accesibilidad a los ascensores de personas, incluyendo personas con discapacidad".

- La dimensión mínima de la cabina del ascensor, con una puerta o con dos puertas enfrentadas serán de 1,00 m de ancho y de $1,25 \mathrm{~m}$ de profundidad.

- El ascensor debe contar con botonera con caracteres en braille y en altorrelieve, contrastados cromáticamente.

- La anchura libre de acceso a la cabina es de $0,80 \mathrm{~m}$, y delante del embarque debe disponerse de un rellano de acceso libre de obstáculos de 1,50 m de diámetro con pavimento táctil señalizador.

- La cabina debe disponer de pasamanos perimetral, así como de indicador sonoro y de información visual de posición de cabina.

- Las puertas han de ser de apertura automática dotadas de sensor de presencia que detecte el bastón blanco y el perro guía (cortina óptica de barrido continuo del sensor entre 0,25 y $1,80 \mathrm{~m}$ ).

6.- Disfrutar del museo.

- En los museos, es importante que todas las personas puedan hacer uso y disfrute de los servicios que se prestan y puedan participar en todas las actividades en igualdad de condiciones y con la mayor seguridad y autonomía posible. Para ello, debe preverse, una forma alternativa para que una persona con discapacidad visual pueda apreciar una pintura; una forma de transmitir los diálogos o sonidos de un video a las personas sordas; o la organización de visitas guiadas con lenguaje sencillo para personas con discapacidad intelectual.

- Las taquillas y mostradores deben tener dos alturas: la más alta $(1,20 \mathrm{~m})$ para personas de pie y la más baja $0,80 \mathrm{~m}$ para usuarios de silla de ruedas. La parte baja tendrá al menos $0,80 \mathrm{~m}$ de ancho y debajo habrá un espacio libre de $0,70 \mathrm{~m}$ de altura y $0,60 \mathrm{~m}$ de fondo que permita la aproximación frontal con la silla de ruedas.

- Los mostradores de atención al visitante estarán equipados con un bucle de inducción magnética que facilite la comunicación de personas con prótesis auditivas. Este servicio estará debidamente señalizado.

- En espacios diáfanos, como vestíbulos y salas de exposiciones, es recomendable facilitar la orientación de las personas con discapacidad visual por medio de franjas guía de encaminamiento.

- Se deben prever áreas de reposo y descanso con bancos o apoyos isquiáticos. Los bancos tendrán reposabrazos que faciliten sentarse y levantarse a las personas mayores y con movilidad reducida. En cada área de descanso deberá preverse una superficie de $0,90 \mathrm{~m} \times 1,50 \mathrm{~m}$ para la ubicación de una silla de ruedas.

- La iluminación general debe ser homogénea e indirecta para evitar deslumbramientos, siendo necesaria una iluminación puntual y dirigida hacia las obras expuestas y los textos explicativos.

- Se debe evitar las luces de neón en espacios sonorizados (salas de conferencias, auditorios, espacios equipados con teléfonos...etc) porque generan interferencias a las personas con discapacidad auditiva que llevan prótesis.

- Todos los servicios del museo (consigna, tienda, cafetería, aseos, salas de conferencias, etc.) deben poder identificarse y utilizarse por todos.

- Debe existir al menos un aseo adaptado para usuarios de silla de ruedas y reservado con el Símbolo Internacional de Accesibilidad.

- Las salas de conferencias con butacas fijas deben tener un espacio reservado para usuarios de silla de ruedas y estar equipadas con un bucle de inducción magnética.

- La cafetería debe tener una barra de doble altura y mesas que permitan la aproximación frontal de usuarios de silla de ruedas.

7.- Servicios prestados a los visitantes con discapacidad.

- Los servicios dirigidos a las personas con discapacidad o con necesidades especiales deben darse a conocer en la página web 
del museo o por medio del correspondiente folleto informativo que se entregue en las taquillas y en los mostradores de información.

- El personal de atención al visitante (personas de recepción, vigilantes de sala, guías, personas de los servicios educativos del museo, etc.) debe estar sensibilizado y formado en la atención a personas con discapacidad.

Recomendaciones sobre servicios dirigidos a personas con discapacidad o con necesidades especiales:

Servicios dirigidos a visitantes con discapacidad auditiva:

- Deben organizarse periódicamente visitas guiadas con interprete de lengua de signos (LS), equipados con una pantalla en la que se reproduce un vídeo subtitulado en el que una persona explica en LS las obras más relevantes del museo.

- Debe disponerse de signoguías para que las personas sordas puedan realizar una visita guiada al museo de forma autónoma.

- El museo debe poner a disposición de las personas que tengan audífonos o implantes con la posición "T" un servicio gratuito de préstamo de lazos personales de inducción magnética para participar en todas las actividades del museo, visitas guiadas, conferencias, talleres, etc.

Servicios dirigidos a visitantes con discapacidad visual:

- El museo debe presentar al menos una parte de las obras de forma que sean fáciles de percibir con la vista, el tacto y el oído. Para ello pueden utilizarse reproducciones de las obras en altorrelieve y con audiodescripción, paneles táctiles o maquetas tiflológicas.

- Deben organizarse periódicamente visitas guiadas comentadas, dirigidas a personas con discapacidad visual, en las que además de explicar la obra, describirla y, si es posible, poder tocarla.

- Debe disponerse de audioguías con información verbal actualizada de las obras expuestas.

- Los rótulos informativos de cada obra tendrán textos de color contrastado respecto al fondo, de gran tamaño y estarán complementados en braille.

- Los rótulos de señalización e información del edificio deben ser fáciles de identificar con la vista e indicar claramente la sala y el recorrido sugerido.

- Debe contarse con un folleto informativo del museo con textos en macro caracteres y con color contrastado respecto al fondo.

- La página web del museo debe ser accesible para las personas ciegas y cumplir con las directrices establecidas por la WAI (Web Accesibility Iniciative).

Servicios dirigidos a personas con discapacidad intelectual:

- Deben organizarse visitas guiadas y talleres adaptados para personas con discapacidad intelectual.

- Debe contarse con un folleto informativo del museo y de sus colecciones con textos de lectura fácil redactados según las directivas europeas de "lectura fácil".

Servicios dirigidos a personas con movilidad reducida:

- Es necesario un servicio de préstamo de sillas de ruedas, de banquetas móviles y de bastones.

- Deben existir bancos situados a lo largo del recorrido para hacer una pausa.

- Debe facilitarse información sobre los itinerarios y aseos accesibles del museo.

8.- Espacios higiénico-sanitarios.

- Cuando se instalen, de forma permanente o temporal, cabinas de aseo público en las áreas de uso peatonal, como mínimo una de cada diez o fracción deberá ser accesible debiendo estar comunicadas con el itinerario peatonal accesible.

- Dispondrán en el exterior de un espacio libre de obstáculos en el que se pueda inscribir un círculo de 1,50 m delante de la puerta de acceso.

- El acceso estará nivelado con el itinerario peatonal accesible y no dispondrá de resaltes o escalones. La puerta de acceso será abatible hacia el exterior, o corredera y tendrá una anchura libre de paso mínima de $0,80 \mathrm{~m}$.

- Junto a la puerta en el interior de la cabina habrá un espacio libre de obstáculos que permita inscribir un círculo de 1,50 m. La altura mínima en el interior de la cabina será de $2,20 \mathrm{~m}$.

- El mecanismo de cierre de la puerta será de fácil manejo y posibilitará su apertura desde el exterior en caso de emergencia. - La cabina dispondrá de un lavabo con un espacio libre inferior que permita la aproximación de una persona en silla de ruedas y su cara superior estará a una altura máxima de $0,85 \mathrm{~m}$.

- El inodoro tendrá el asiento a una altura entre 0,45 y $0,50 \mathrm{~m}$ y dispondrá a cada lado de un espacio lateral de $0,80 \mathrm{~m}$ de ancho para la transferencia desde una silla de ruedas. Se instalarán barras de apoyo abatible junto al espacio lateral de transferencia.

9.- Iluminación, información y señalización.

- La iluminación artificial deberá ser uniforme, resaltando las obras expuestas y los textos explicativos.

- En los accesos se dispondrá de información para la orientación y localización de los itinerarios peatonales accesibles que conecten accesos, instalaciones, servicios y actividades disponibles.

- La información se podrá presentar a través de señalización visual y acústica y/o táctil en relieve o en Braille.

- Los mapas y planos deben reproducirse al menos, de forma visual y táctil.

- El lenguaje y nomenclatura utilizados en las señales deben ser claros, fáciles de entender y uniformes a lo largo de todo el recorrido.

- Es necesario señalizar el acceso, salida, espacios, instalaciones y servicios accesibles con el Símbolo Internacional de Accesibilidad indicado por las normas internacionales ISO 7000:2014, ISO 7001:2007 e ISO 7010:2011.

10.- Evacuación en caso de emergencia.

Revista Internacional de Turismo, Empresa y Territorio, vol. 4, nº 2, 2020, pp. 128-157

https://www.uco.es/ucopress/ojs/index.php/riturem/index 
- Debe existir el correspondiente plan de evacuación de la instalación en caso de emergencia con especial atención a la
evacuación de las de las personas con movilidad o comunicación reducidas.
- El personal responsable de la guarda del museo debe estar instruido en el rescate asistido y en la evacuación de personas
con discapacidad en caso de emergencia.
- Debe señalizarse adecuadamente, tanto los equipos de protección contra incendios, los recorridos de evacuación así como
las salidas de emergencia.

Fuente: Elaboración propia.

A continuación, se realiza un estudio de dimensión exploratoria a través de diferentes visitas a los tres museos de Caen para efectuar el trabajo de campo de verificación y control in situ de los diferentes aspectos que nos permitirá evaluar su grado de accesibilidad universal así como el grado de adaptación de sus instalaciones, espacios y servicios a personas con discapacidad, obteniéndose una serie de fotografías complementarias a la comprobación de los diferentes indicadores. Con toda la información recabada, se realizará el correspondiente diagnóstico de accesibilidad para determinar la posibilidad de las personas con discapacidad o con movilidad reducida de aproximarse, entrar, utilizar, disfrutar, salir o evacuar en su caso, de forma lo más autónoma, segura y digna posible.

Prestando especial atención a las barreras de los puntos de recepción, mesas, pedestales, alturas de los objetos, vitrinas y luces, los molestos reflejos, las esquinas y ángulos de las salas y de los muebles, los rótulos pequeños, las alfombras superpuestas, los incómodos asientos y áreas de descanso, la falta de espacios para leer u hojear una publicación, pantallas donde encontrar información o intercambiar ideas. La supresión o atenuación de estas barreras que limitan, tanto la visita como el uso y disfrute del propio museo, por parte de las personas con discapacidad, viene exigida no sólo por los principios de igualdad de derechos y oportunidades y no discriminación que rigen en el ámbito internacional, europeo y francés, sino que representa también una medida eficaz para incorporar a nuevos grupos a las actividades relacionadas o derivadas del turismo cultural, contribuyendo así al crecimiento de un sector económico con una directa incidencia en la generación de riqueza y empleo para toda la sociedad.

La evaluación de la accesibilidad suele verse limitada a la comprobación de la conformidad con los estándares de accesibilidad. La conformidad con estos estándares es importante ya que en muchos casos, es un requisito legal y en otros es sólo una buena forma de comprobar que se han resuelto, adecuadamente, todos los problemas de accesibilidad. La accesibilidad significa, básicamente, que las personas con discapacidad pueden utilizar un entorno, producto o servicio. Abarca todo tipo de discapacidad o diversidad funcional, incluyendo discapacidades visuales, auditivas, físicas, cognitivas, neurológicas y de habla, así como situaciones temporales.

La accesibilidad museística se debe plantear en dos aspectos esenciales, por un lado la accesibilidad al entorno físico, y por otro, la accesibilidad a los contenidos, con la debida adecuación de las técnicas expositivas y la elaboración de recursos de accesibilidad para su adaptación a los diferentes tipos de visitantes. Con el análisis de los indicadores de accesibilidad universal propuestos podremos determinar el grado de accesibilidad de los espacios, itinerarios o elementos accesibles, que cumplen con las condiciones básicas de accesibilidad y no discriminación de las personas en situación de discapacidad, considerando en todo caso, la diversidad de sus usuarios en cuanto a dimensiones, edad, habilidad, fuerza y otras características. 
Partiendo del análisis de la cadena de accesibilidad se recoge información objetiva de los diferentes requisitos técnicos que deben cumplir los museos para ser considerados como accesibles tanto para personas con discapacidad física como aquellas que presentan algún tipo de discapacidad sensorial $\mathrm{u}$ otras necesidades especiales, que nos determinen en caso de incumplimiento de la normativa, la posibilidad de uso y disfrute con alguna dificultad o en su caso determinar su inaccesibilidad. En la tabla 2 se recogen los diferentes niveles o grados de accesibilidad en el acceso, uso, disfrute y evacuación del museo en función del cumplimiento de las exigencias funcionales y dimensionales requeridas.

\begin{tabular}{|l|}
\hline \multicolumn{1}{|c|}{ Tabla 2. Niveles de accesibilidad en los museos. } \\
\hline 1.- Museo accesible. \\
\hline $\begin{array}{l}\text { Aquel museo que se ajusta a los requerimientos técnicos, funcionales y dimensionales que garantizan su utilización autónoma, } \\
\text { segura y cómoda, a las personas de movilidad o comunicación reducida o con cualquier otra limitación. }\end{array}$ \\
\hline 2.- Museo practicable. \\
\hline $\begin{array}{l}\text { Aquel que, sin ajustarse a los requerimientos anteriormente mencionados, no impiden su utilización autónoma, pero con } \\
\text { suficiente seguridad y comodidad para las personas con movilidad y/o comunicación reducida o con cualquier otra limitación. }\end{array}$ \\
\hline 3.- Museo practicable con apoyo. \\
\hline $\begin{array}{l}\text { Aquel museo que, sin ajustarse a los anteriores requerimientos, no impide su utilización puntual, de forma autónoma o con } \\
\text { una mínima ayuda de terceros, a personas de movilidad y/o comunicación reducida o con cualquier otra limitación. }\end{array}$ \\
\hline 4.- Museo inaccesible. \\
\hline $\begin{array}{l}\text { Aquellos espacios, itinerarios o elementos del museo que no permiten, a las personas con movilidad y/o comunicación } \\
\text { reducida o con cualquier otra limitación, su utilización de forma autónoma y segura ni con una mínima ayuda de otras } \\
\text { personas. }\end{array}$ \\
\hline
\end{tabular}

Fuente: Elaboración propia.

La Charte d'accueil des personnes handicappées dans les équipements culturels (Commission nationale Culture et Handicap, Francia, 2006) (Jourdy y Sophys-Veret, 2007) establece los aspectos relacionados con la participación de las personas con discapacidad en los equipamientos culturales, desplazarse, identificar, explorar y comprender el espacio, acceder a las instalaciones, acceso y usabilidad de la museografía, comunicarse y participar, descansar, satisfacer las necesidades fisiológicas básicas, estar y sentirse seguro, uso y disfrute del museo en condiciones de comodidad.

Con toda la información recabada, se realizará, el correspondiente diagnóstico de accesibilidad para determinar la posibilidad de las personas con movilidad o comunicación reducida de aproximarse, entrar, utilizar, usar, disfrutar, salir o evacuar en su caso, los museos de forma lo más autónoma, digna y segura posible, y poder concluir su nivel de accesibilidad.

\section{Resultados}

Seguidamente se realizó la visita a cada uno de los museos de Caen para efectuar las observaciones directas como trabajo de campo de verificación y control in situ de los diferentes aspectos que nos permitirá evaluar su grado de accesibilidad universal así como el grado de adaptación de sus instalaciones, espacios y servicios a personas con discapacidad, recogiéndose una serie de fotografías complementarias a la comprobación de los diferentes ítems para su posterior análisis. 
El análisis se realiza desde el punto de vista del visitante, no analizando la accesibilidad para otro tipo de usos o actividades que se desarrollen al margen de las visitas turísticas. Se pretende unificar criterios para evaluar la accesibilidad al patrimonio y con ello poder asignar un determinado grado de accesibilidad a cada uno de ellos y proporcionar la mayor información posible al usuario.

\subsection{Análisis de la Accesibilidad de "Le Mémorial".}

El Memorial de Caen es un museo y memorial de guerra que permite descubrir la Segunda Guerra Mundial desde sus orígenes hasta el final del conflicto, marcado por la Batalla de Normandía. Construido según el proyecto del arquitecto Jacques Millet, fue inaugurado en 1988 y forma parte de la International Network of Museums for Peace. El Memorial, situado en la explanada Eisenhower de Caen, ciudad mártir casi totalmente destruida por los bombardeos de la Segunda Guerra Mundial, es un museo sobre la historia del siglo XX, dedicado a la paz.

Una vez efectuada la visita a las instalaciones del museo "Le Mémorial" y tras el estudio y análisis de los datos recabados, podemos efectuar el siguiente diagnóstico (Tabla 3), en relación a la situación de accesibilidad universal siguiendo la estructura que anteriormente hemos marcado de indicadores y sub-indicadores de accesibilidad:

Tabla 3. Diagnóstico de la Accesibilidad Universal de "Le Mémorial".

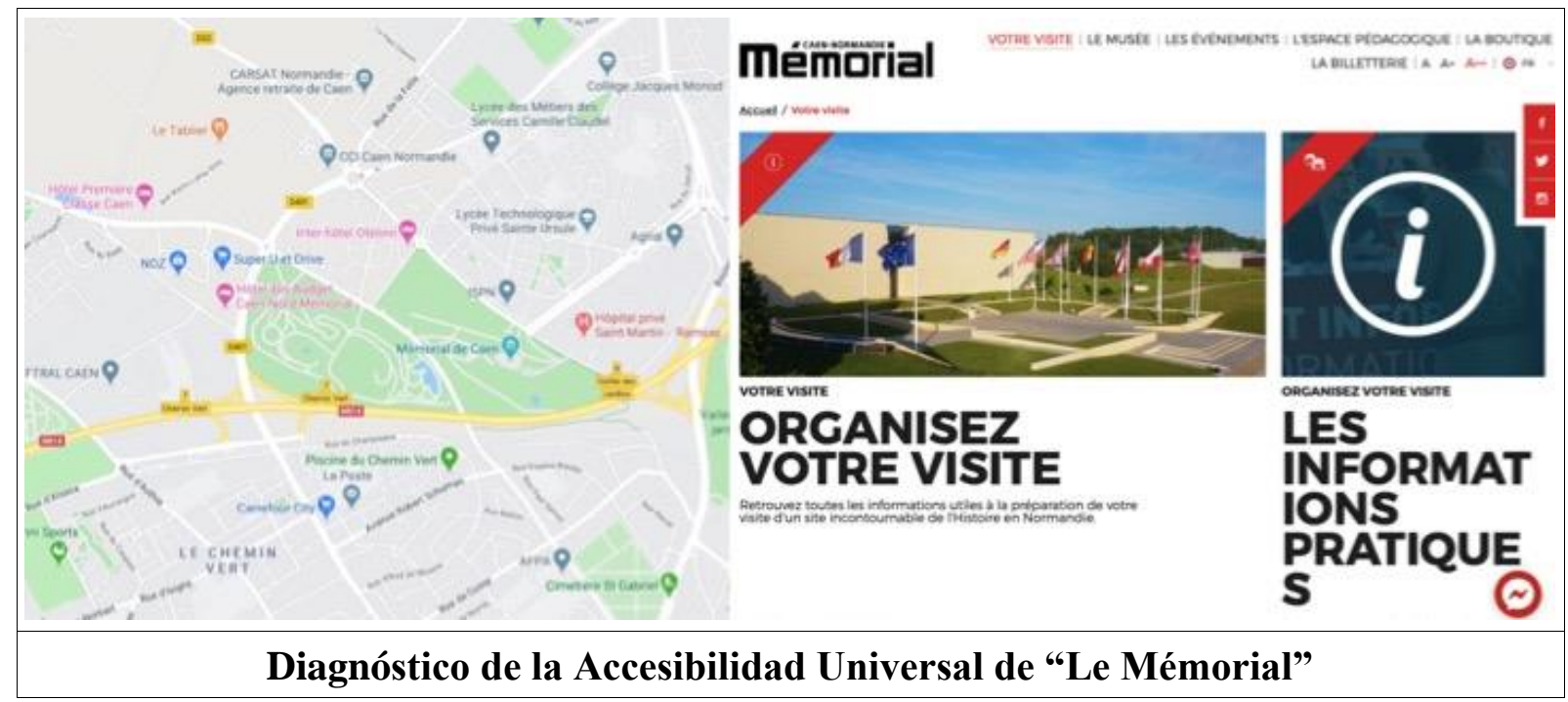




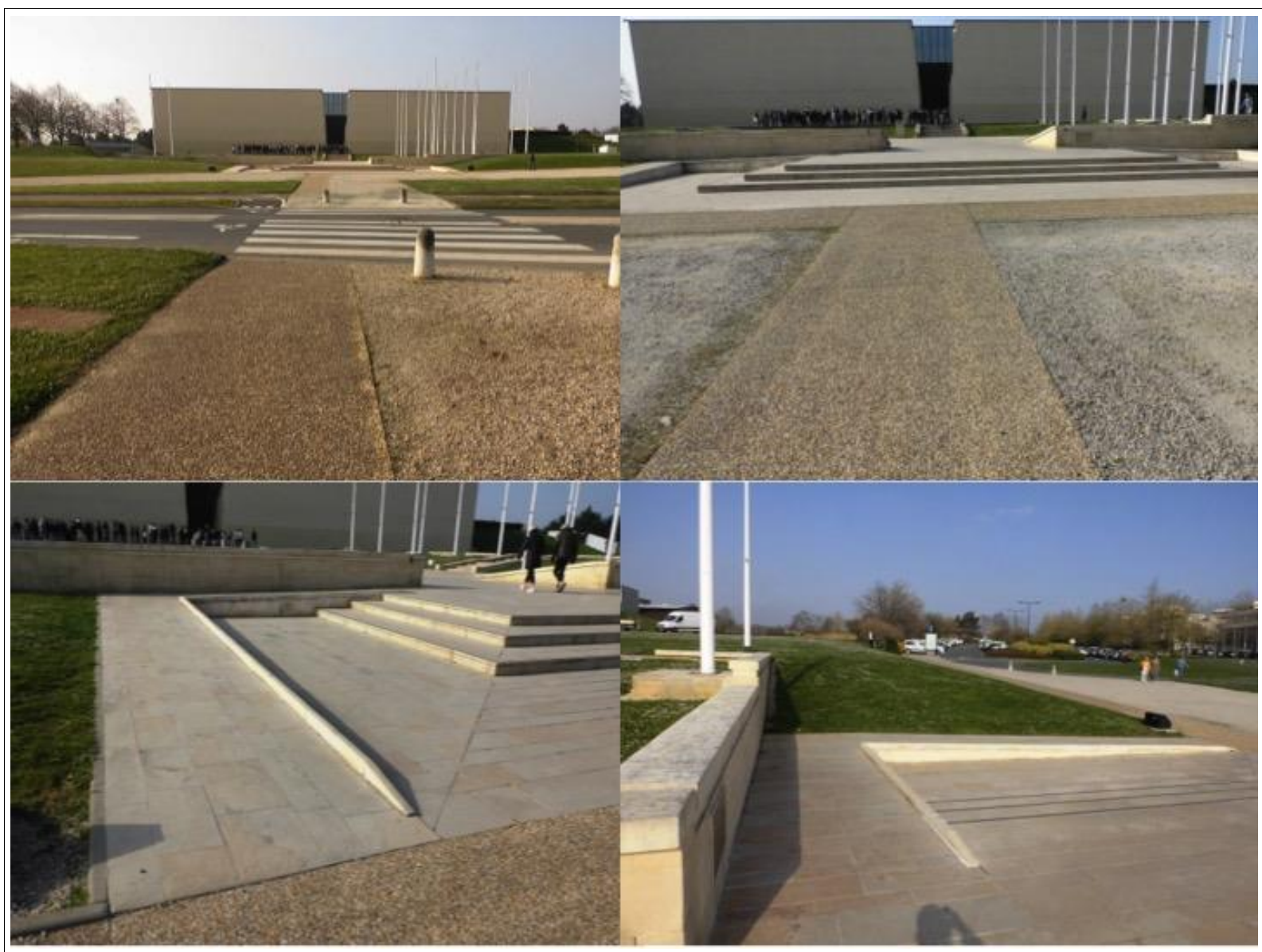

\section{1.- Cómo llegar al museo}

2.- Plazas de aparcamiento reservadas.

- Entorno exterior accesible a usuarios de silla de ruedas, pero - Existen dos plazas de estacionamiento reservadas para no a personas con discapacidad visual.

- Ausencia de pavimento direccional de encaminamiento. personas usuarias de silla de ruedas o de movilidad reducida conectadas con la entrada principal mediante itinerario - Existe una rampa para salvar los escalones de acceso que peatonal accesible.

carece de franja señalizadora podo-táctil de diferente textura y - El itinerario peatonal accesible no está debidamente color para la advertencia y señalización del embarco y señalizado. Dificultad para orientarse. desembarco.

- No existe un plano de localización que marque el recorrido y las distancias desde el estacionamiento reservado a la entrada principal del museo.

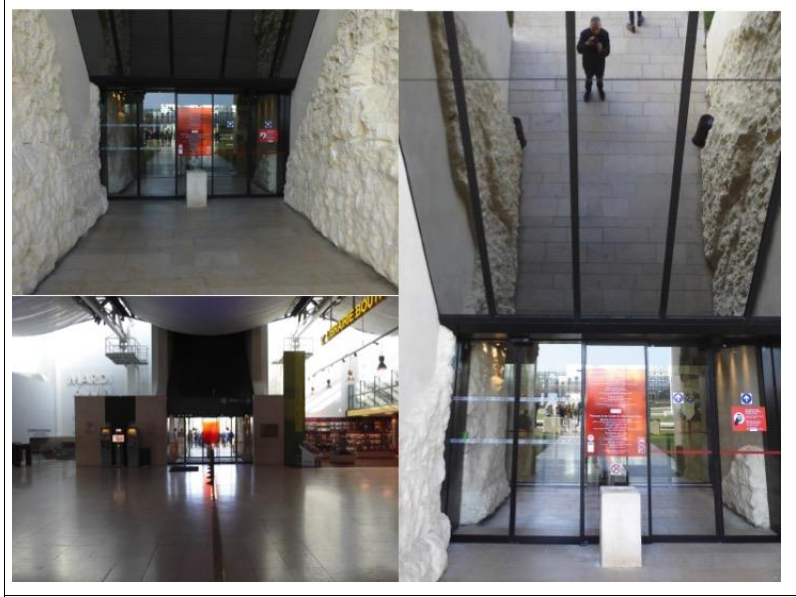

3.- Entrada al museo.

- Entrada principal a nivel.

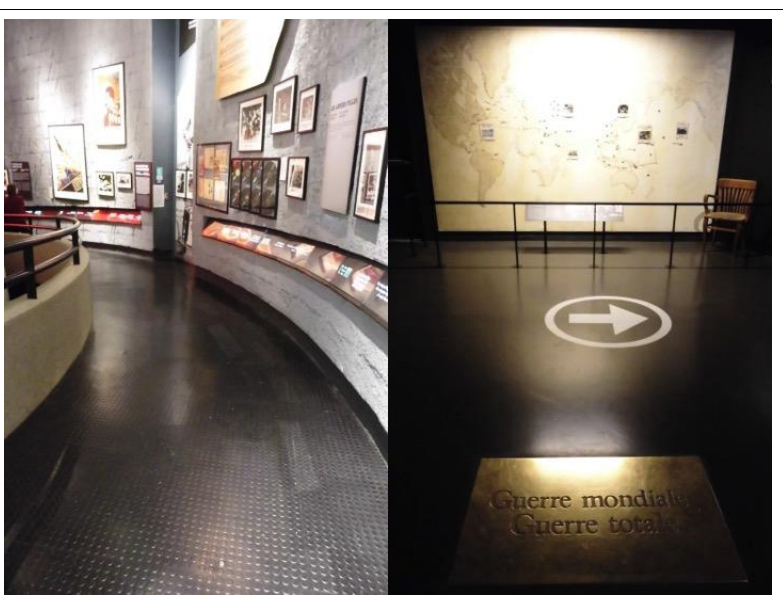

4.- Comunicación horizontal.

Pavimento sintético deslizante que dificulta el

- Puertas se acceso automáticas con anchura libre superior a desplazamiento de la silla de ruedas. 
$0,80 \mathrm{~m}$.

- Delante de la puerta de acceso existe un espacio de maniobra horizontal mayor de $1,50 \mathrm{~m}$.

- Puerta corredera con efecto espejo que dificulta la localización del acceso. No está señalizada con dos franjas horizontales de color contrastado.

- Hall de entrada con deslumbramiento por el sol.

- Rótulos pequeños que dificulta la localización de los diferentes servicios.

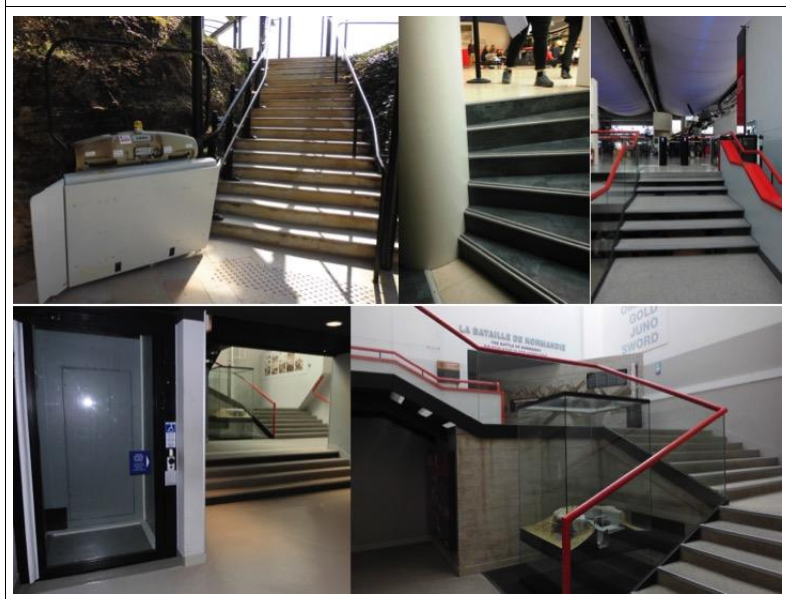

\section{5.- Comunicación vertical.}

- Escalera compensada muy peligrosa de acceso al auditorium.

- No existe pavimento señalizador de advertencia al embarque y desembarque de la escalera.

- Escalones sin tabica.

-Los desplazamientos entre las distintas plantas son accesibles por medio del ascensor alternativo a las escaleras y en su caso plataforma elevadora vertical, señalizados con el Símbolo Internacional de Accesibilidad (SIA).

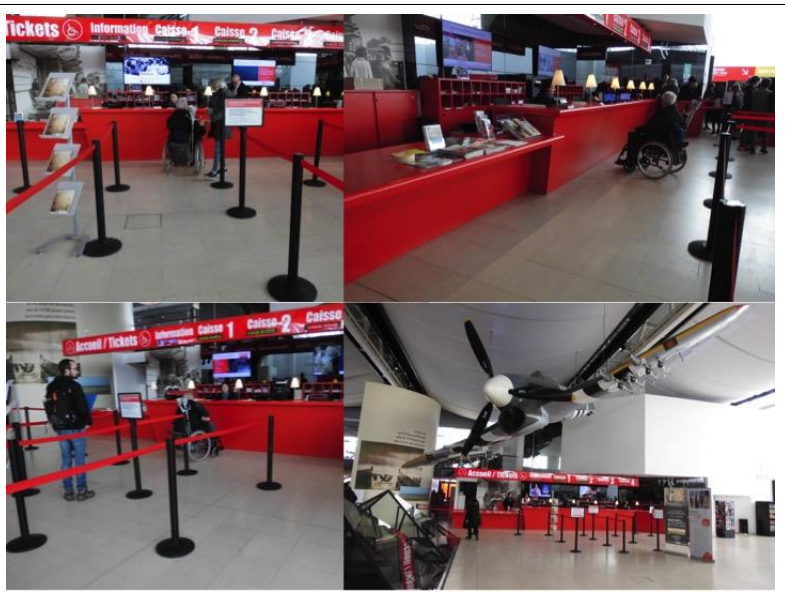

7.- Servicios prestados a los visitantes con discapacidad.
- No existen bandas direccionales de encaminamiento.

- Señalización direccional de visita en el suelo de grandes dimensiones y contraste de color.(Colocadas posteriormente para subsanar la dificultad de orientación). desplazamiento de usuarios de silla de ruedas y de niños o personas de talla baja.

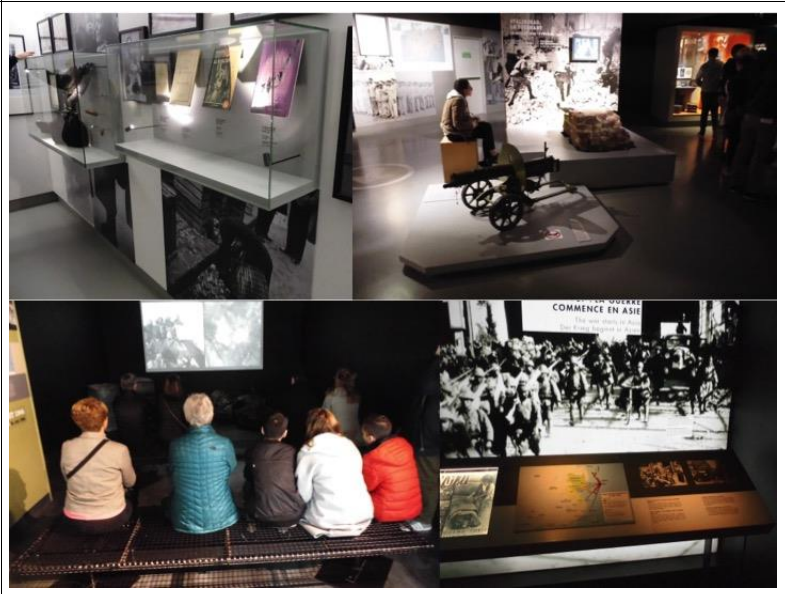

\section{6.- Disfrutar del museo.}

- Mostrador de recepción no es accesible, cuenta con una zona a mas baja altura pero se utiliza de expositor, no de atención a personas de baja talla o usuarios de silla de ruedas.

- Mesas expositoras muy altas para la posición de sentado.

- Vitrinas y protecciones con cristal muy peligrosas para personas con dificultad visual.

- No existe en el cine- auditotium ni plazas ni espacios reservados para personas usuarias de silla de ruedas.

- Zonas de descanso con bancos sin reposabrazos distribuidas por las salas.

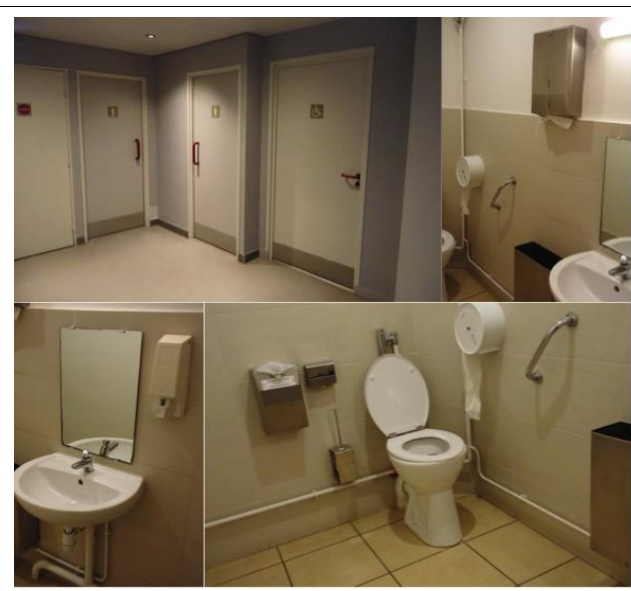

\section{8.- Espacios higiénico-sanitarios.}

- En el momento de la visita, el personal de recepción no - Existen dos aseos adaptados aunque presentan algunas atiende debidamente al visitante usuario de silla de ruedas.

- Se dispone de guía audio descriptiva y en LSF.

- Se dispone de bucle magnético solo en el auditorium.

deficiencias.

- La puerta muy pesada, abre haca dentro.

- Falta barra de apoyo en la zona de transferencia del inodoro.

- No existe información de los contenidos del museo en fácil lectura.

- Espacio de giro en interior de diámetro 1,50 m.

- No señalizados con el Símbolo Internacional de - No se organizan talleres o visitas adaptadas a personas con Accesibilidad (SIA). 


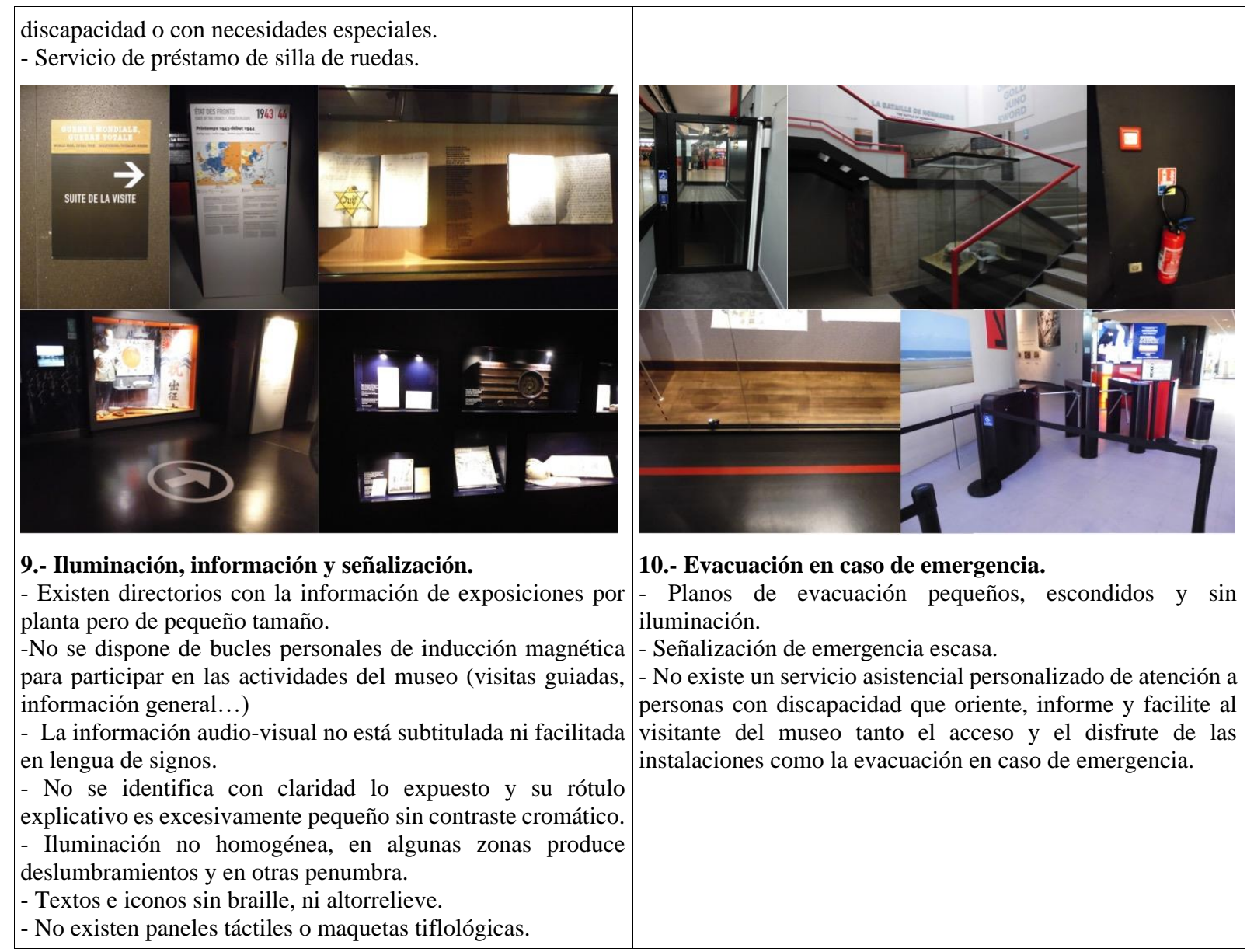

\section{Fuente: Elaboración propia.}

Para acceder y disfrutar del museo, se deben tener presente las características de la conexión con el exterior, las circulaciones horizontales y verticales, la señalización y comunicación, el acceso a los contenidos expuestos, así como la correcta evacuación en caso de emergencia. En este sentido, el museo "Le Mémorial de Caen" es accesible físicamente para personas con movilidad reducida y usuarios de silla de ruedas, pero no así para personas con discapacidad visual, auditiva o en su caso, discapacidad mental o cognitiva.

\subsection{Análisis de la Accesibilidad del "Musée de Normandie".}

El Museo de Normandía de Caen fue fundado en 1946, y desde 1963 se ubica en el Castillo de la ciudad, construido alrededor de 1060 por Guillermo el Conquistador. El museo cuyas colecciones se enriquecen regularmente, ofrece tanto un panorama histórico de la región como un enfoque dedicado a la vida diaria de las personas desde la prehistoria hasta el crecimiento de la industria en el siglo XX constituyendo una gran inmersión etnográfica e histórica en el corazón de la región.

Una vez efectuada la visita a las instalaciones del "Musée de Normandie", y tras el estudio y análisis de los datos recabados in situ, podemos efectuar el siguiente diagnóstico (Tabla 4) en relación a la situación de accesibilidad universal:

Tabla 4. Diagnóstico de la Accesibilidad del Musée de Normandie. 


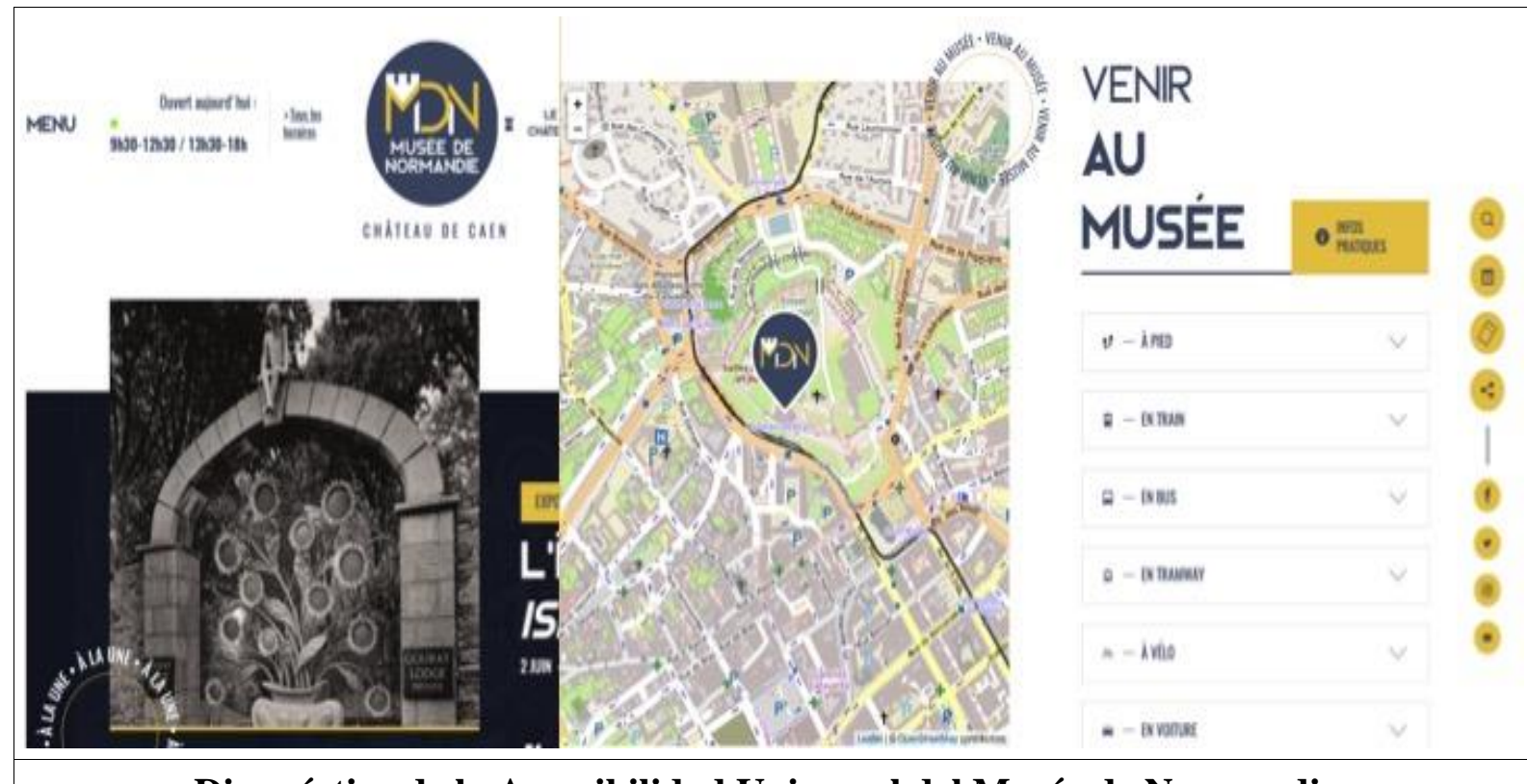

Diagnóstico de la Accesibilidad Universal del Musée de Normandie.

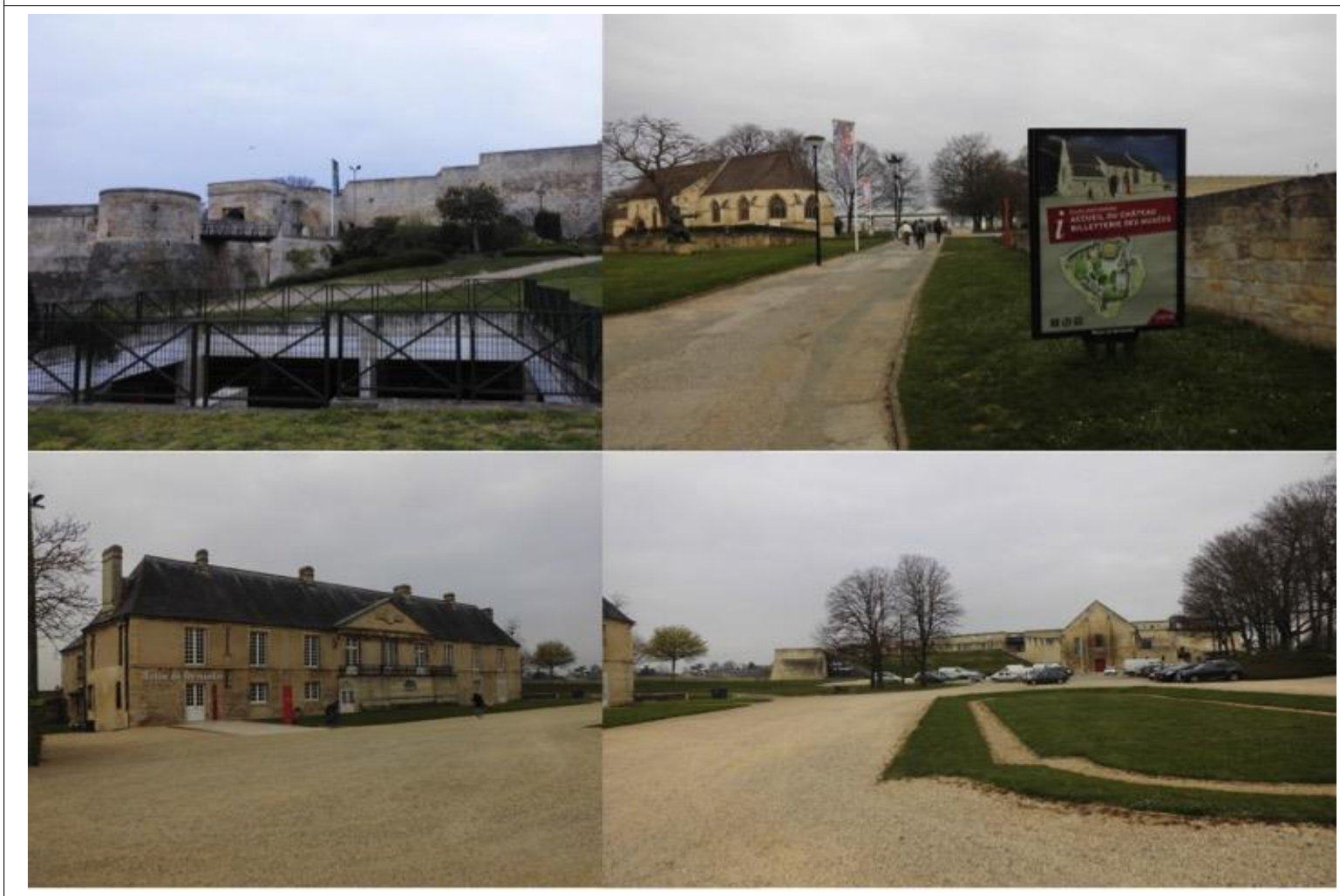

1.- Cómo llegar al museo.

2.- Plazas de aparcamiento reservadas.

- El pavimento de las zonas exteriores del edificio es un - No existen plazas de estacionamiento reservadas para pavimento blando a base de albero que dificulta la personas usuarias de silla de ruedas o de movilidad reducida deambulación de las personas usuarias de silla de ruedas o próximas a la entrada.

personas con movilidad reducida.

- Excepcionalmente se permite llegar en coche hasta la misma entrada del museo. 


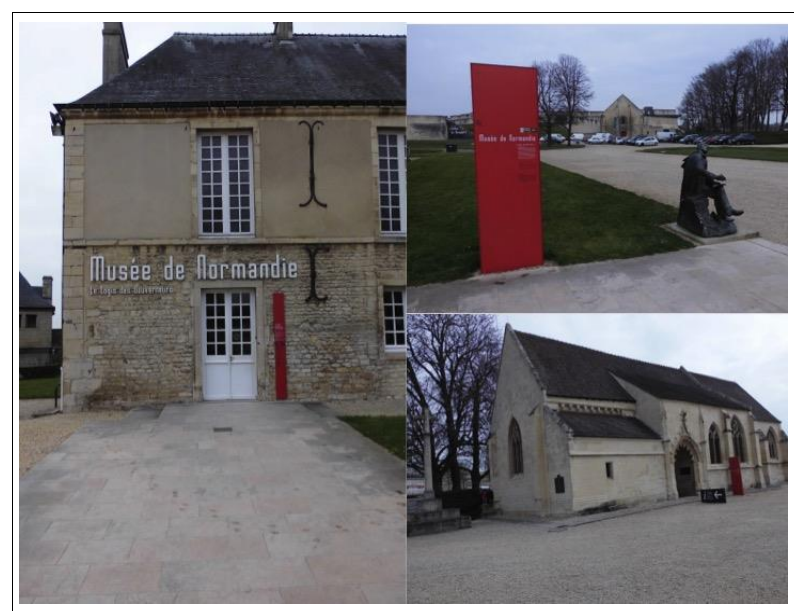

3.- Entrada al museo.

- Entrada principal a nivel.

- Abriendo las dos hojas, la anchura libre de la puerta de acceso es superior a $0,80 \mathrm{~m}$.

- La puerta de entrada es excesivamente pesada.

- Delante de la puerta de acceso existe un espacio de maniobra horizontal mayor de $1,50 \mathrm{~m}$.

- La anchura de la puerta de entrada de la billetería "Église Saint-Georges", es superior a $0,80 \mathrm{~m}$. Aunque como medida de gestión las personas con movilidad reducida acceden directamente al museo.

- No existe un itinerario peatonal accesible entre la billetería y el edificio del museo.

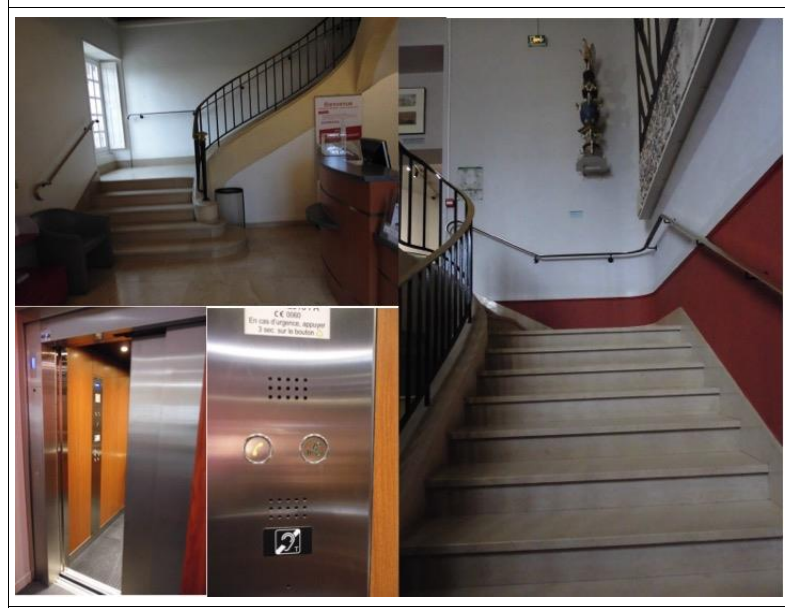

5.- Comunicación vertical.

- Las escaleras son de directriz recta, y presentan pasamanos en ambos lados.

- No existe un contraste visual entre las mesetas y los escalones superior e inferior de cada tramo de escalera.

- No existe pavimento táctil indicador de advertencia al inicio y final de las escaleras.

- No existen textos en relieve o símbolos táctiles fijados a los pasamanos que aporten información sobre el recorrido a realizar.

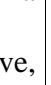

- El ascensor es accesible, dotado con pulsadores en relieve, en Braille y con indicación sonora $\mathrm{T}$.

- La anchura libre de acceso a la cabina es de $0,80 \mathrm{~m}$.

- La cabina solo dispone de pasamanos en el lateral del panel de accionamiento del ascensor.

- La información escrita en cabina se realiza con pequeños caracteres, dificultando su lectura.

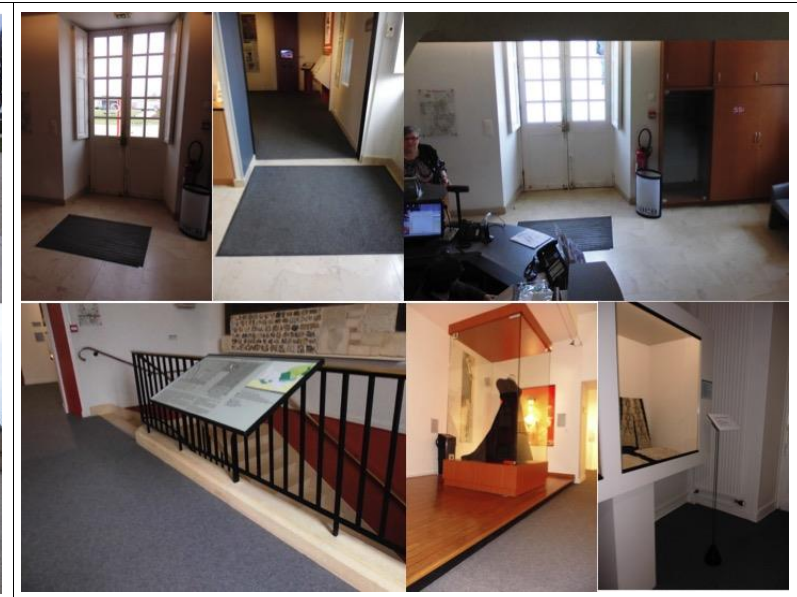

\section{4.- Comunicación horizontal.}

- En el interior del museo no existen pavimentos podo-táctiles integrados en un sistema de encaminamiento para conducir a puntos y espacios de interés de las diferentes exposiciones.

- La circulación horizontal establecida en el museo facilita la orientación y la libertad de movimientos de todas las personas visitantes.

- La superficie del suelo es resistente al deslizamiento, no reflectante y firme. Aunque existen felpudos y alfombras que dificultan el desplazamiento.

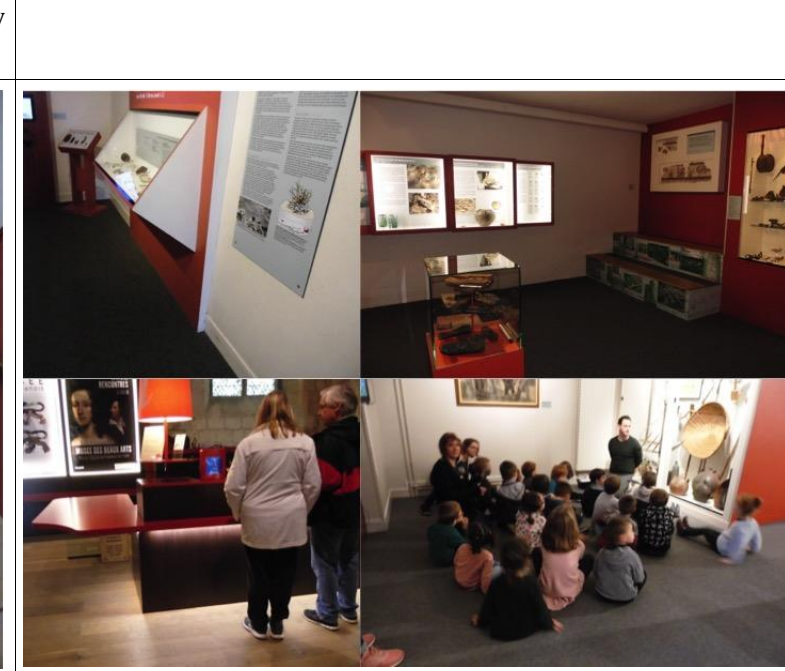

\section{6.- Disfrutar del museo.}

- Mostrador de recepción accesible, cuenta con una zona a mas baja altura para la atención a visitantes de baja talla o usuarios de silla de ruedas.

- Mesas expositoras muy altas para la posición de sentado.

- Vitrinas y protecciones con cristal muy peligrosas para personas con dificultad visual.

- Existe bucle de inducción magnética, para la atención de personas con dificultades auditivas, tanto en la billetería como en la recepción.

Existe información multimedia, en canal sonoro y subtitulado.

- Disponibilidad de tabletas, pantallas y tableros táctiles. 


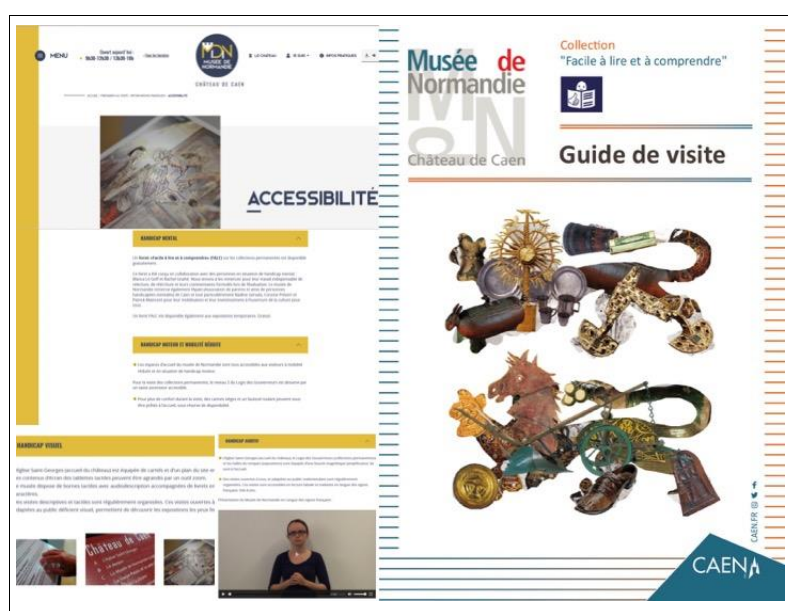

7.- Servicios prestados a los visitantes con discapacidad.

- No existen pavimentos tacto-visuales integrados en un sistema de encaminamientos para conducir a puntos concretos de interés (mostradores y puntos de atención, sala de espera o aseos adaptados) a las personas con problemas de visión o de comprensión del entorno.

- No se dispone de un punto de llamada-recepción accesible para demandar ayuda.

- Se dispone de maquetas e información en sistema Braille para personas ciegas, en LSF y bucles de inducción magnética para personas sordas.

- No existe personal formado en la lengua de signos para atender a personas sordas o con deficiencia auditiva.

- No se dispone de apoyos isquiáticos ni de asientos con reposabrazos en las zonas de espera y atención al público.

- Disponible el servicio de atención personalizada y visitas guiadas a personas con discapacidad previa reserva.

- Folletos disponibles en lectura fácil.

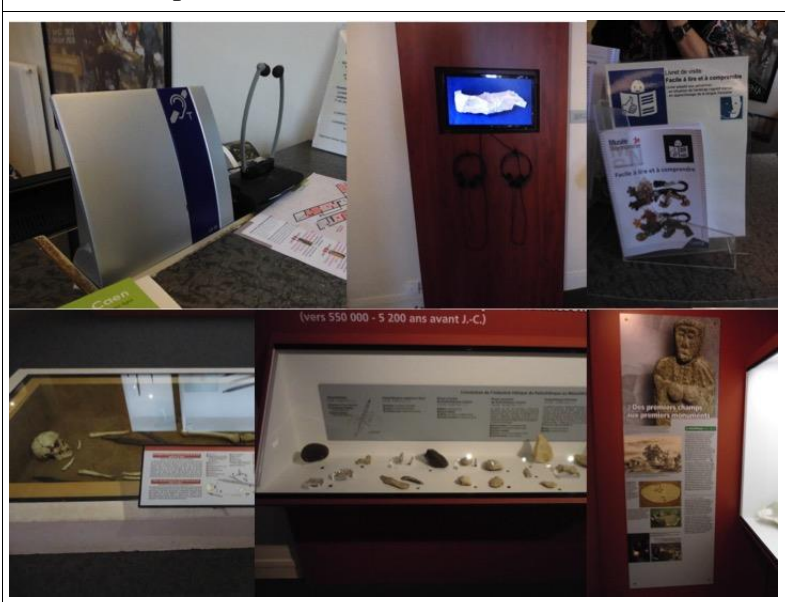

9.- Iluminación, información y señalización.

- La señalización direccional y funcional no dirige con claridad a los diferentes pisos y secciones del museo.

-La iluminación provoca deslumbramientos, reflejos y sombras no permitiendo una visión correcta tanto de los colores como de las letras y pictogramas de los carteles informativos.

- No se utilizan colores diferentes para la identificación de puertas y de distintas plantas o espacios del museo, con el fin de ayudar a los usuarios con deficiencia tanto visual como cognitiva.

- La altura de las vitrinas y los expositores no son apropiadas

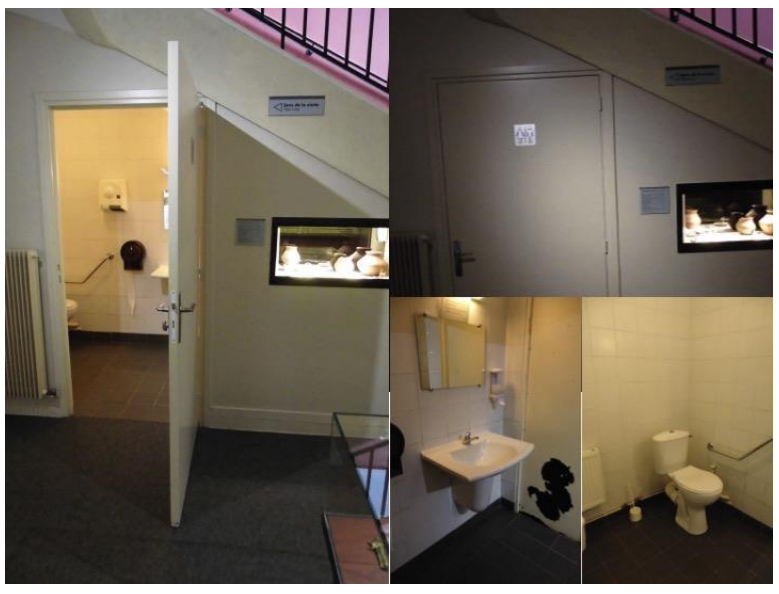

8.- Espacios higiénico-sanitarios.

- En la la billetería del museo "Église Saint-Georges" no existe servicio higiénico adaptado a usuario de silla de ruedas.

- El único servicio higiénico-sanitario accesible existente en el museo no se adapta a todas las variedades de usuarios y sus discapacidades.

- El espacio de maniobra libre de obstáculos del aseo no permite en su caso la transferencia frontal, oblicua y lateral (espacio de giro de diámetro inferior a $1,50 \mathrm{~m}$ ).

- Al tratarse de un aseo de uso publico, debería permitir la doble transferencia al inodoro.

- Las barras de apoyo inclinadas no son aconsejables, no existiendo en este caso, barra de apoyo abatible.

- No existe dispositivo mediante el cual se transmita una llamada de asistencia.

- No señalizado con el Símbolo Internacional de Accesibilidad (SIA).

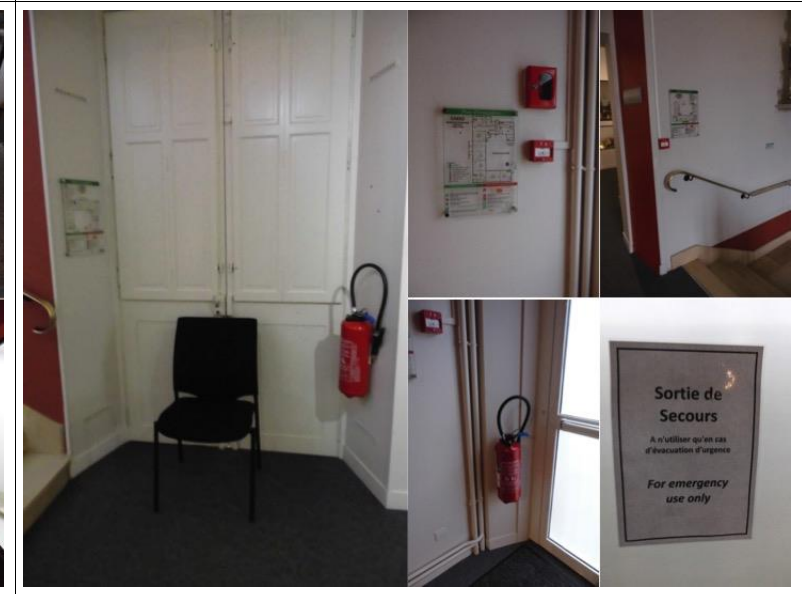

10.- Evacuación en caso de emergencia.

- No existe información escrita sobre el plan de evacuación en caso de emergencia, ni se dispone de zonas de refugio accesibles a personas usuarias de silla de ruedas. Aunque existe un servicio asistencial personalizado de atención a personas con discapacidad que oriente, informe y facilite al visitante del museo tanto el acceso y el disfrute de las instalaciones como la evacuación en caso de emergencia. - Señalización adecuada de los recorridos de evacuación, salidas de emergencia así como la localización de los diferentes sistemas de extinción de incendios con los que 
para las personas de talla baja o en posición de sentado.

- Algunas vitrinas presentan aristas que pueden provocar pequeños.

situaciones de riesgo para los visitantes con choques y golpes.

- La señalización del museo no es totalmente legible y entendible por las personas que tienen deficiencias visuales o intelectuales.

- La información de texto se realiza con tipografía en caracteres pequeños no siendo fácil de leer, en todo caso debería complementarse con diferentes colores y símbolos gráficos para facilitar la comprensión a todas las personas.

Fuente: Elaboración propia.

Para el uso y disfrute del museo por todas las personas, se deben tener presente las características de la conexión con el exterior, las circulaciones horizontales y verticales, la señalización y comunicación, el acceso a los contenidos expuestos, así como la correcta evacuación en caso de emergencia. En este sentido, el "Musée de Normandie de Caen" es accesible físicamente para personas con movilidad reducida y usuarios de silla de ruedas, y para visitantes con discapacidad auditiva y mental pero no así para visitantes ciegos o con discapacidad visual.

\subsection{Análisis de la Accesibilidad del Musée Beaux Arts de Caen.}

En un edificio contemporáneo diseñado en el recinto del Castillo Ducal de Guillermo el Conquistador se encuentra el Museo de Bellas Artes de la ciudad de Caen, capital de Calvados. Desde el siglo XIV hasta nuestros días, cerca de 350 cuadros presentan una panorámica completa de la pintura europea. Las colecciones francesa, italiana, flamenca y holandesa abarcan los siglos XVI y XVII, así como un conjunto único de grabados, lo que lo convierte en uno de los museos más importantes de Francia. Tras la visita a sus instalaciones y una vez realizado el estudio de los diferentes indicadores y subindicadores de accesibilidad universal, podemos efectuar el siguiente diagnóstico (Tabla 5):

Tabla 5. Diagnóstico de la Accesibilidad del Musée Beaux Arts de Caen.

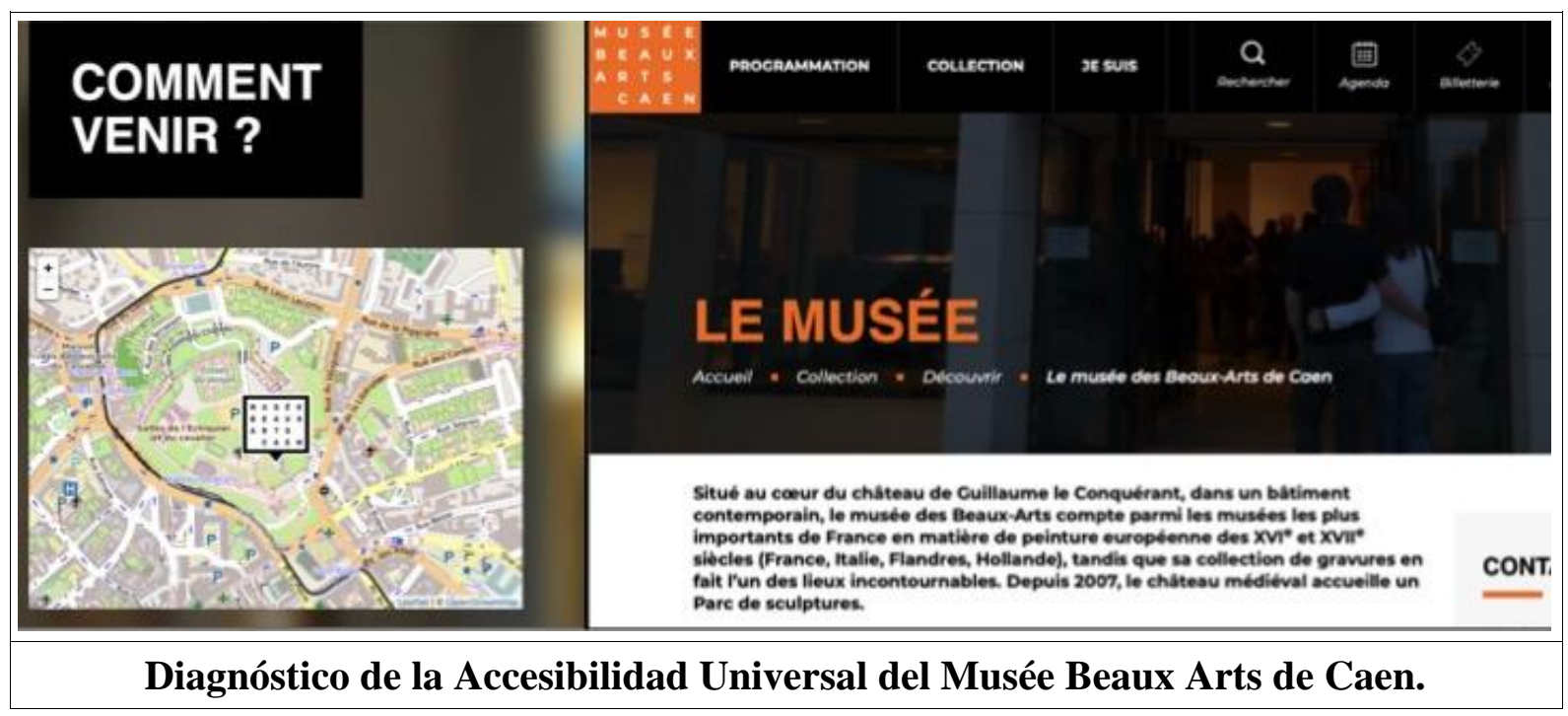




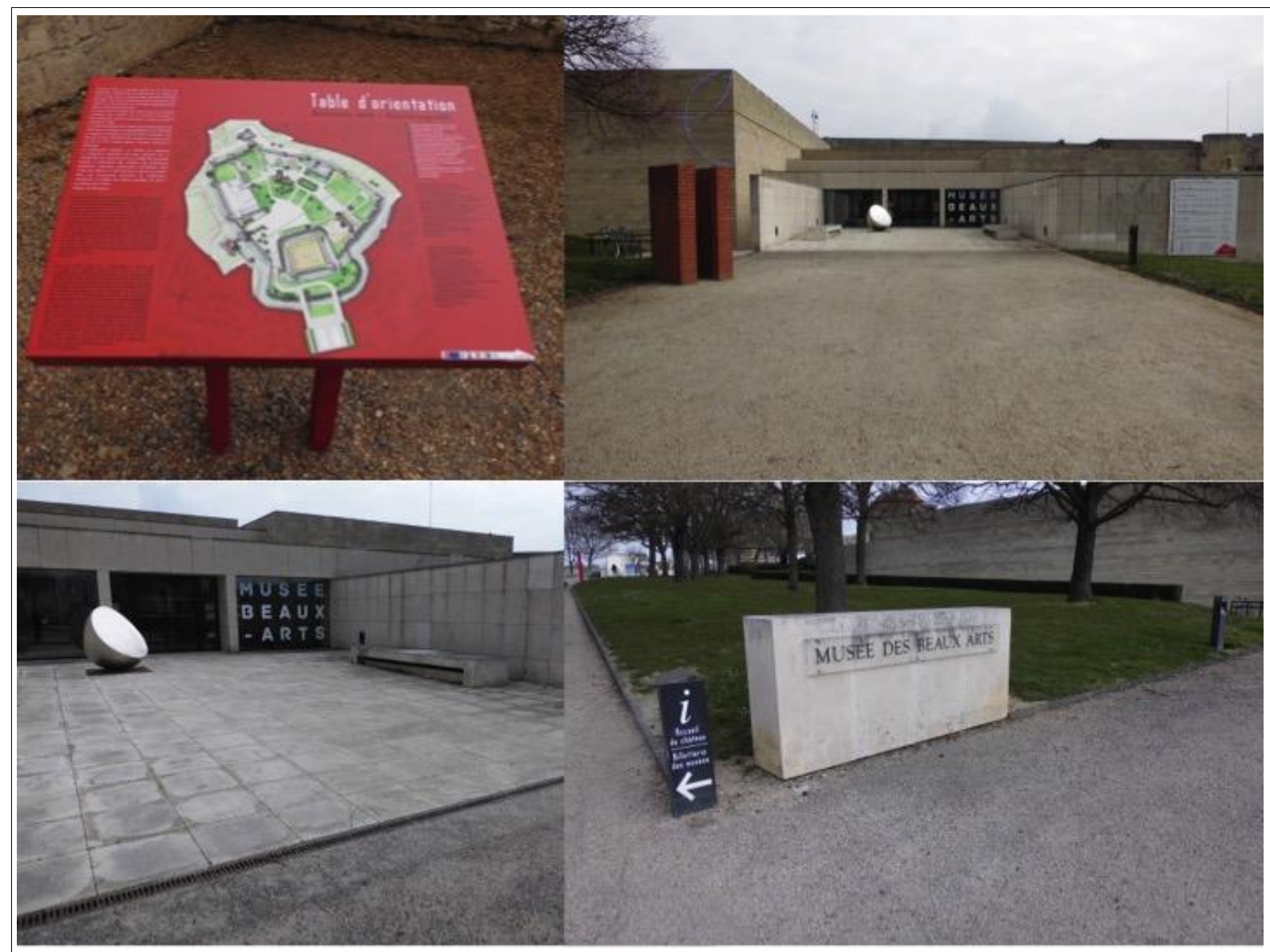

1.- Cómo llegar al museo.

2.- Plazas de aparcamiento reservadas.

- El pavimento de las zonas exteriores del edificio es un - No existen plazas de estacionamiento reservadas para pavimento blando a base de albero que dificulta la personas usuarias de silla de ruedas o de movilidad reducida deambulación de las personas usuarias de silla de ruedas o próximas a la entrada. personas con movilidad reducida.

- Excepcionalmente se permite llegar en coche hasta la misma entrada del museo.
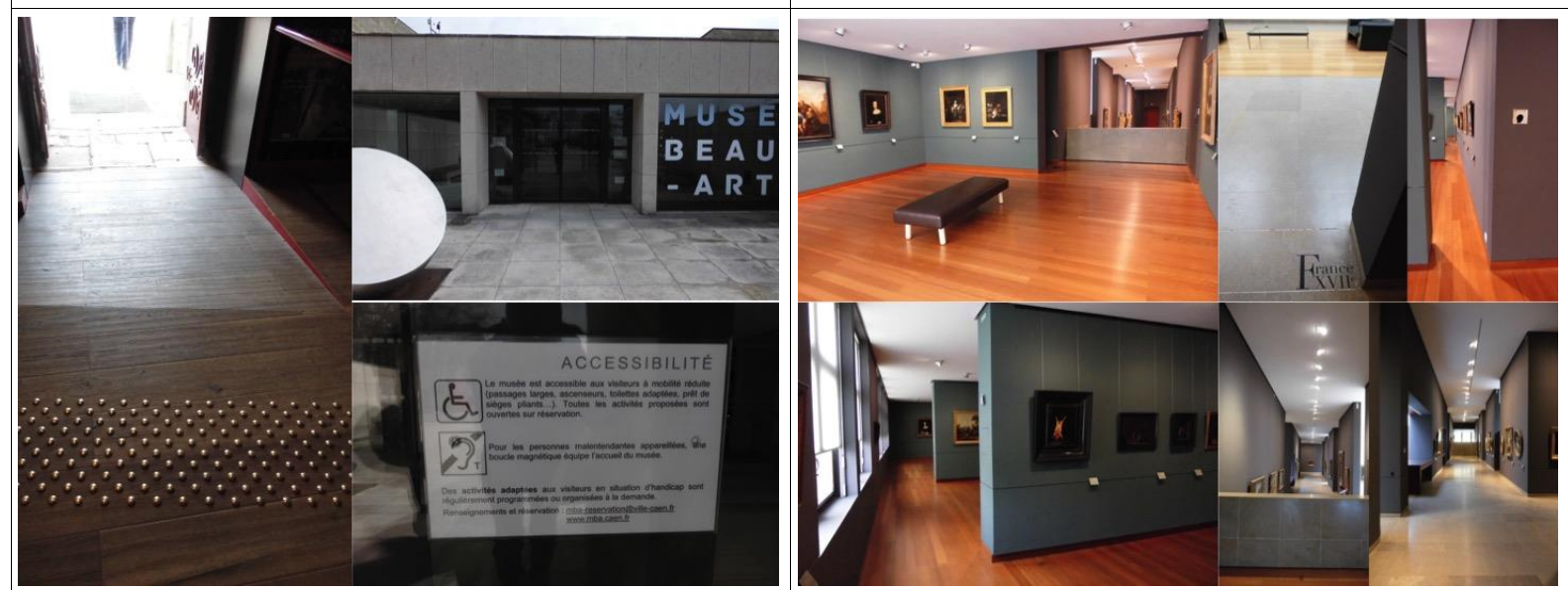

\section{3.- Entrada al museo.}

- Entrada principal a nivel.

- Puerta acristalada, corredera con anchura libre de paso superior a $0,80 \mathrm{~m}$.

- Delante de la puerta de acceso existe un espacio de maniobra horizontal mayor de $1,50 \mathrm{~m}$. - La anchura de la puerta de entrada de la billetería "Église personas visitantes.

\section{4.- Comunicación horizontal.}

- En el interior del museo no existen pavimentos podo-táctiles integrados en un sistema de encaminamiento para conducir a puntos y espacios de interés de las diferentes exposiciones.

- La circulación horizontal establecida en el museo no facilita la orientación y la libertad de movimientos de todas las 
Saint-Georges", es superior a $0,80 \mathrm{~m}$. Aunque como medida - La iluminación produce destellos y deslumbramiento sobre de gestión las personas con movilidad reducida acceden los paramentos horizontales y verticales que impiden una directamente al museo. visión adecuada.

- No existe un itinerario peatonal accesible entre la billetería y - La superficie del suelo debe ser resistente al deslizamiento y el edificio del museo.

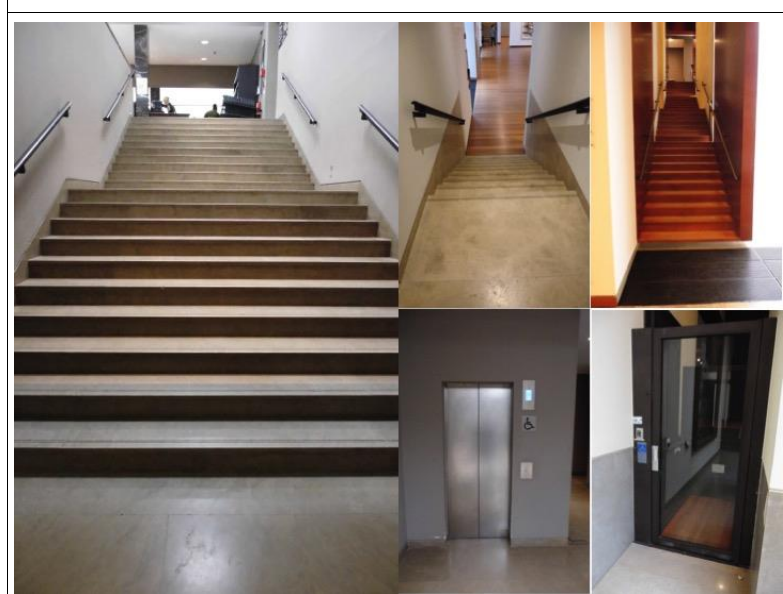

5.- Comunicación vertical.

- Las escaleras son de directriz recta, y presentan pasamanos en ambos lados.

escalones superior e inferior de cada tramo de escalera. - Mesas expositoras muy altas para la posición de sentado.

Igualmente no existe pavimento táctil indicador de - Vitrinas y protecciones con cristal muy peligrosas para advertencia al inicio y final de las escaleras.

- No existen textos en relieve o símbolos táctiles fijados a los pasamanos que aporten información sobre el recorrido a realizar. personas con dificultad visual.

- Ascensor accesible, dotado con pulsadores en altorelieve, con información en Braille e indicación sonora.

- La dimensión de la cabina del ascensor solo permite su uso por una persona en silla de ruedas, sin ningún acompañante.

- La anchura libre de acceso a la cabina es de $800 \mathrm{~mm}$.

- La cabina solo dispone de pasamanos en el lateral del panel de accionamiento del ascensor.

- La información escrita en cabina se realiza con pequeños caracteres, dificultando su lectura.

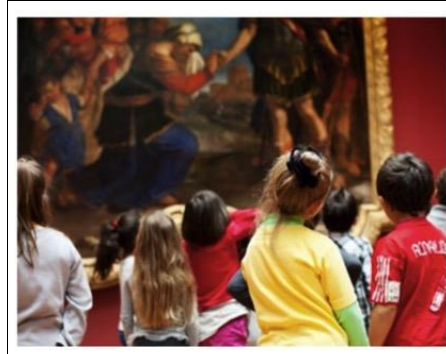

Personnes en situation de handicap

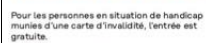

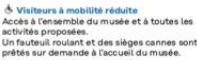

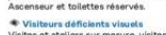

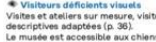

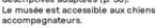
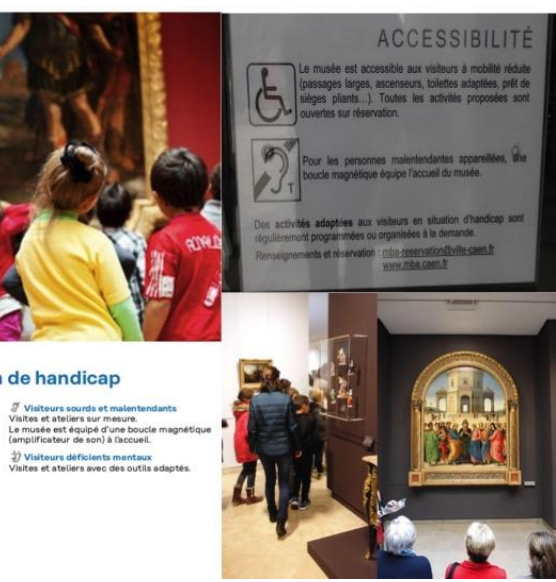

7.- Servicios prestados a los visitantes con discapacidad.

- No existen pavimentos tacto-visuales integrados en un - En la billetería del museo "Église Saint-Georges" no existe sistema de encaminamientos para conducir a puntos concretos servicio higiénico adaptado a usuario de silla de ruedas.

de interés (mostradores y puntos de atención, sala de espera o En el Musée de Beaux Arts, existe un aseo accesible pero en aseos adaptados) a las personas con problemas de visión o de el momento de la visita, estaba prohibido su uso al publico

Revista Internacional de Turismo, Empresa y Territorio, vol. 4, nº 2, 2020, pp. 128-157

https://www.uco.es/ucopress/ojs/index.php/riturem/index 
comprensión del entorno.

- No se dispone de un punto de llamada-recepción accesible para demandar ayuda.

- No se dispone de información en sistema Braille para personas ciegas, ni bucles de inducción magnética para personas sordas, en su caso.

- No existe personal formado en la lengua de signos para atender a personas sordas o con deficiencia auditiva.

- No se dispone de apoyos isquiáticos ni de asientos con reposabrazos en las zonas de espera y atención al público.

- En el momento de la visita, no estaba disponible el servicio de atención personalizada a personas con discapacidad.

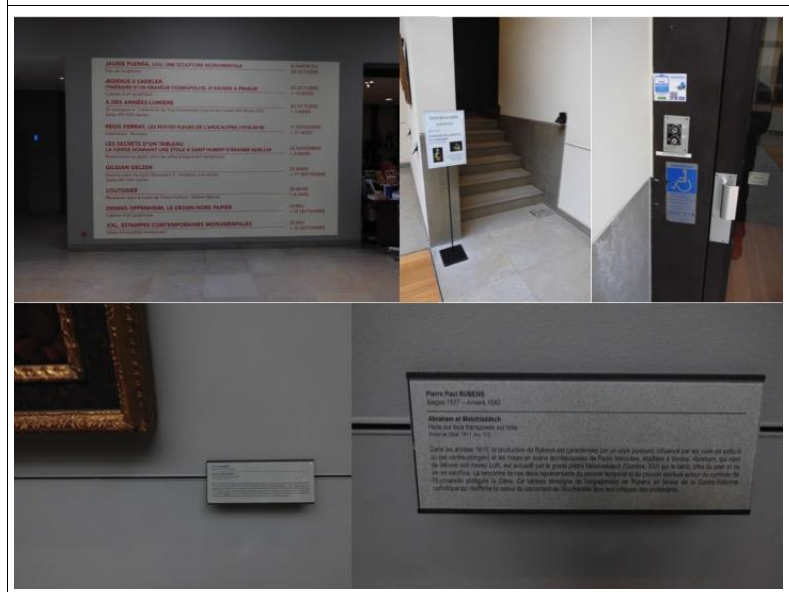

\section{9.- Iluminación, información y señalización.}

- Junto a la puerta de entrada del museo no existe señalización informativa ni señalización de orientación accesible.

- La señalización direccional y funcional no dirige con claridad a los diferentes pisos y secciones del museo.

-La iluminación provoca deslumbramientos, reflejos y sombras no permitiendo una visión correcta tanto de los colores como de las letras y pictogramas de los carteles informativos.

- Para las personas sordas o con deficiencia auditiva, es esencial disponer de una buena iluminación para que se pueda ver tanto los dispositivos visuales de información como para poder leer los labios o interpretar las expresiones faciales.

- No se utilizan colores diferentes para la identificación de puertas y de distintas plantas o espacios del museo, con el fin de ayudar a los usuarios con deficiencia tanto visual como cognitiva.

- No se señalizan las distintas plantas del museo con números grandes claramente definidos relativos al nivel de la planta al comienzo y final de la escalera, ni en los pasamanos ni a cada lado del marco exterior de todos los accesos a la cabina del ascensor en cada planta.

- La altura de las vitrinas y los expositores no son apropiadas para las personas de talla baja o en posición de sentado.

- Algunas vitrinas presentan aristas que pueden provocar situaciones de riesgo para los visitantes con choques y golpes. - La señalización del museo no es totalmente legible y entendible por las personas que tienen deficiencias visuales o mentales.

- La información de texto se realiza con tipografía en caracteres pequeños no siendo fácil de leer, en todo caso debería complementarse con diferentes colores y símbolos gráficos para facilitar la comprensión a todas las personas. visitante, solo se permitía su uso al personal del propio museo. "Interdit au public. Staff only".

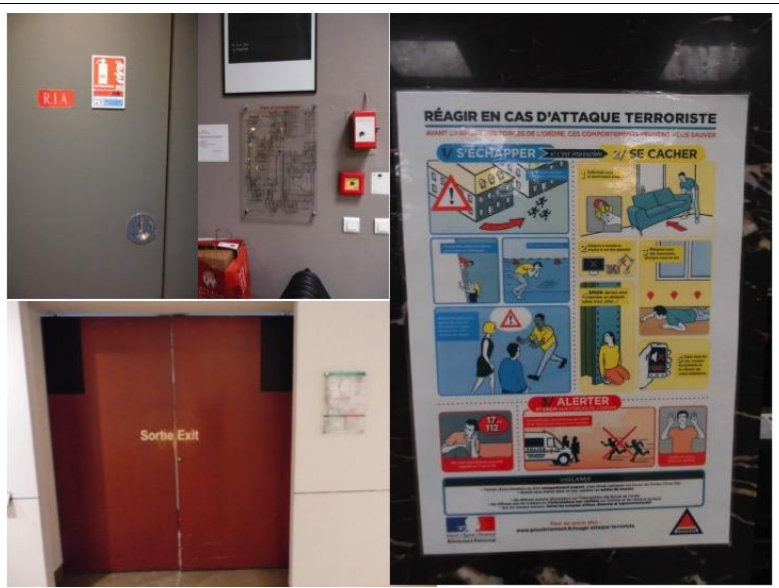

\section{0.- Evacuación en caso de emergencia.}

- No existe información escrita sobre el plan de evacuación en caso de emergencia, ni se dispone de zonas de refugio accesibles a personas usuarias de silla de ruedas.

- No existe un servicio asistencial personalizado de atención a personas con discapacidad que oriente, informe y facilite al visitante del museo tanto el acceso y el disfrute de las instalaciones como la evacuación en caso de emergencia.

- Señalización de pequeñas dimensiones de los recorridos de evacuación, salidas de emergencia así como la localización de

los diferentes sistemas de extinción de incendios con los que cuenta el museo.

Los planos de evacuación en caso de emergencia están realizados en metacrilato y con el destello de la iluminación es difícil su visualización y comprensión. 
- No existe señalización accesible ni en relieve ni en Braille.

- No se disponen símbolos táctiles o en relieve en pasamanos,

planos o maquetas.

Fuente: Elaboración propia.

Para acceder y disfrutar del museo, se deben tener presente las características de la conexión con el exterior, las circulaciones horizontales y verticales, la señalización y comunicación, el acceso a los contenidos expuestos, así como la correcta evacuación en caso de emergencia. En este sentido, el "Musée Beaux Arts de Caen" es accesible físicamente para personas con movilidad reducida y usuarios de silla de ruedas, pero no así para personas con discapacidad visual, auditiva o en su caso, discapacidad intelectual.

\section{Análisis y Discusión.}

El turismo accesible para todos sólo existe cuando la accesibilidad y el diseño universal se ha incorporado a toda la cadena de valor del turismo. Sin duda, para que la visita al museo tenga sentido y resulte satisfactoria, los visitantes no solo han de poder circular en estos espacios sino también acceder a los contenidos expuestos. Para ello podrán instalarse paneles informativos con información sobre los elementos expositivos que sean adecuados y accesibles por su localización, diseño, tamaño de texto, contraste, etc., teniendo en cuenta las necesidades de aproximación y altura en vitrinas, acercando el contenido a los usuarios con discapacidad visual facilitando incluso el tacto de las obras cuando sea posible sin dañar los originales o realizando maquetas, modelos a escala o láminas didácticas que permitan identificar el contenido de los originales. Siendo muy recomendable el uso de dispositivos multimedia como las audioguías y videoguías que facilitan el acceso a la información a todos los visitantes y especialmente a los que tienen alguna discapacidad sensorial o mental.

Una vez estudiado el grado de accesibilidad universal de los museos de Caen ninguno de ellos es universalmente accesible a todas las discapacidades (fisica, sensorial, cognitiva), no obstante, y siguiendo los niveles de accesibilidad establecidos en la tabla 2, podemos calificarlos con los niveles recogidos en la Tabla 6:

Tabla 6. Diagnóstico del nivel de accesibilidad de los museos de Caen.

\begin{tabular}{|l|c|c|c|c|}
\hline Museo: & $\begin{array}{c}\text { Accesibilidad } \\
\text { física }\end{array}$ & \multicolumn{2}{|c|}{$\begin{array}{c}\text { Accesibilidad } \\
\text { sensorial:visual/auditiva }\end{array}$} & $\begin{array}{c}\text { Accesibilidad } \\
\text { cognitiva }\end{array}$ \\
\hline Le Mémorial & ACCESIBLE & $\begin{array}{c}\text { PRACTICABLE CON } \\
\text { APOYO }\end{array}$ & PRACTICABLE & $\begin{array}{c}\text { PRACTICABLE } \\
\text { CON APOYO }\end{array}$ \\
\hline $\begin{array}{l}\text { Musée de } \\
\text { Normandie }\end{array}$ & ACCESIBLE & PRACTICABLE & ACCESIBLE & ACCESIBLE \\
\hline $\begin{array}{l}\text { Musée de Beaux } \\
\text { Arts de Caen }\end{array}$ & ACCESIBLE & $\begin{array}{c}\text { PRACTICABLE CON } \\
\text { APOYO }\end{array}$ & PRACTICABLE & $\begin{array}{c}\text { PRACTICABLE } \\
\text { CON APOYO }\end{array}$ \\
\hline
\end{tabular}

Fuente: Elaboración propia.

Es necesario que los museos informen en sus paginas web accesibles, de la posibilidad o no de realizar visitas guiadas especializadas así como, de la posibilidad de participar en talleres didácticos accesibles y adaptados a visitantes con discapacidad cognitiva que permitan 
tanto el acceso como la usabilidad y el disfrute de la museografía en condiciones de comodidad y seguridad. En este sentido, la falta de información independiente, objetiva y veraz en materia de accesibilidad, implica un mayor riesgo para el turista con discapacidad. En esta sociedad de la información, los datos sobre las condiciones de accesibilidad física, sensorial y mental deben ser lo mas reales posibles.

En este sentido se aporta en la tabla 7 la referencia que la "Guide Handicap 2019" editada por el Ayuntamiento de Caen hace sobre la accesibilidad universal de los museos de Caen. Llama la atención que la información transmitida no coincide plenamente con el nivel de accesibilidad constatado por nuestro estudio.

Tabla 7. Información sobre accesibilidad universal de los museos de Caen.

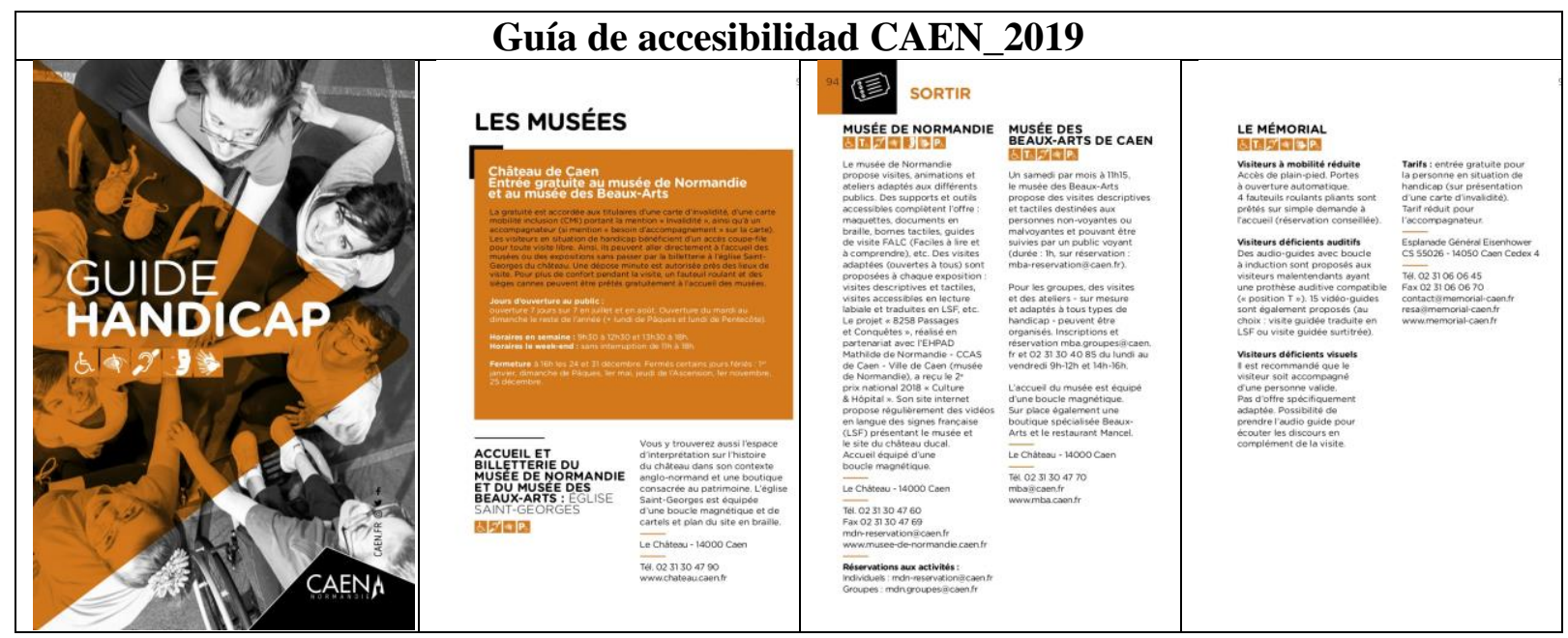

Fuente: Guide Handicap. Caen 2019.

\section{Conclusiones.}

1.- Los museos de Caen (Le Mémorial, Musée de Normandie y el Musée de Beaux Arts) no son plenamente accesibles universalmente a todas las personas con discapacidad.

2.- El Musée de Normandie es accesible a personas tanto usuarias de silla de ruedas o con movilidad reducida, como a personas con discapacidad auditiva y cognitiva, siendo practicable para personas con discapacidad visual.

3.- El museo Le Mémorial y el museo de Beaux Arts son accesibles a personas usuarias de silla de ruedas o con movilidad reducida, practicables para personas con discapacidad auditiva y practicables con apoyo para personas con discapacidad visual o intelectual.

4.- La implementación los conceptos del diseño universal o diseño para todos en los museos, permite el acceso a la cultura a todas las personas y debería ser una práctica obligada desde la misma concepción del proyecto del museo y de la colección museística, hasta su materialización en la cadena de la accesibilidad, es decir desde el transporte público hasta la puerta del museo, los recorridos interiores tanto horizontales como verticales, la señalética, los servicios como 
puntos de atención, mostradores, aseos, taquillas, tiendas, restaurantes y toda la museografía como alturas medias, huecos de mobiliario, tipografía accesible, selección de originales y reproducciones táctiles, maquetas, etc.

5.- La falta de accesibilidad en los museos es una forma de discriminación, introduciendo el concepto de museo accesible para todos se garantiza la igualdad de oportunidades y no discriminación de todas las personas en situación de discapacidad. El uso y disfrute, en un sentido amplio, que la sociedad hace de los museos se logra mediante la participación plena y efectiva de todas las personas.

6.- Es imprescindible que los museos informen en sus paginas web accesibles, de la posibilidad o no de realizar visitas guiadas especializadas así como, de la posibilidad de participar en talleres didácticos accesibles y adaptados a visitantes con discapacidad que permitan tanto el acceso como la usabilidad y el disfrute de la museografía en condiciones de comodidad y seguridad. Esta información debe ser lo mas objetiva y veraz posible.

7.- Es fundamental la dotación de personal sensibilizado y especializado, con la formación lo más amplia y concreta posible, capaz de conocer la diversidad humana y especialmente, los diferentes tipos de discapacidad, para darse cuenta de las necesidades y soluciones específicas para cada colectivo.

\section{Referencias}

Actas del II Congreso Internacional de Educación y Accesibilidad. Museos y Patrimonio. URL:http://www.mastermuseos.es/blog/publicaciones/actas-del-ii-congreso-internacional-deeducacion-y-accesibilidad/

Alonso López, F. (1999). Los beneficios de renunciar a las barreras. Instituto de Mayores y Asuntos Sociales (IMSERSO). Secretaría General de Asuntos Sociales. Ministerio de Trabajo y Asuntos Sociales. Madrid.

Álvarez de Morales Mercado, Cristina (2013). La accesibilidad en el museo desde una perspectiva sociológica. Revista de Estudios Jurídicos no 13/2013 (Segunda Época). Universidad de Jaén (España) ISSN 1576-124X (impresa). ISSN 2340-5066 (digital): rej.ujaen.es

Asociación Española de Normalización y Certificación (2012). Norma UNE ISO 21542. Edificación. Accesibilidad del entorno construido (AENOR 2012). URL:http://www.aenor.es/aenor/normas/normas/fichanorma.asptipo=N\&codigo=N0050139\#. WZ6LfVHVDmg

Comisión Europea DG XXIII-UNIDAD DE TURISMO (1996). Por una Europa Accesible a Turistas con Discapacidades. Manual para la Industria del Turismo. Bruselas Bélgica: CECACE-CEEA.

Comisión Europea (1991). Por una Europa Accesible a Turistas con Discapacidades. URL: http://www.ec.europa.eu.

Comisión Europea (1996). Comunicación sobre Igualdad de Oportunidades para personas con discapacidades. URL: http://www.ec.europa.eu. 
European Institute for Design and Disability Stockholm (2004). Declaration 2004:Design for All. URL:http://www.designforall.org/en/documents/Stockholm_Declaration_ang.pdf

Fernández Alles, M.T. (2009). Turismo Accesible: Análisis de la Accesibilidad Hotelera en la Provincia de Cádiz. Cádiz: Servicio de Publicaciones de la Universidad de Cádiz.

Fernández Alles, M. T. (2013). Los museos accesibles en España: el caso Guggenheim. Pasos. Revista de Turismo y Patrimonio Cultural, 11(2), 399-415. https://doi.org/10.25145/j.pasos.2013.11.026

Hernández-Galán, J. (dir.) (2017). Observatorio de Accesibilidad Universal del Turismo en España. Madrid: CERMI y Fundación ONCE.

INSERSO (1983). Clasificación Internacional de Deficiencias, Discapacidades y Minusvalías. Manual de Clasificación de las consecuencias de la enfermedad. OMS. Madrid: Instituto Nacional de Servicios Sociales.

Marcos, D. y González, D.J. (2003). Turismo Accesible: Hacia un Turismo para Todos. Comité Español de Representantes de Personas con Discapacidad. Madrid: Instituto de Mayores y Servicios Sociales. Secretaría General de Asuntos Sociales. Ministerio de Trabajo y Asuntos Sociales.(CERMI).

Marjan, Z. (Coord.) (1996). Concepto Europeo de Accesibilidad (CCPT). Ministerio de Trabajo y Asuntos Sociales. Madrid.

Martínez Carrillo, M.J. y Boujrouf, S. (2017): Turismo accesible para todos. Análisis del grado de accesibilidad de las infraestructuras turísticas de transporte de Marrakech. Revista Turydes: Turismo y Desarrollo, 23. En línea: http://www.eumed.net/rev/turydes/23/accesibilidadmarrakech.html

Martínez Carrillo, M.J. y Boujrouf, S. (2018): Turismo accesible, turismo para todos. Análisis de la accesibilidad en los establecimientos hoteleros de Marrakech. Revista Contribuciones a las Ciencias Sociales. En línea:http://www.eumed.net/rev/cccss/2018/02/turismo-accesiblemarrakech.html

Martínez Carrillo, M.J. (2018): Turismo accesible para todos. Análisis del grado de accesibilidad universal del Museo de Historia Natural de Rouen (Francia). Revista Turydes: Turismo y Desarrollo, 25 (diciembre / dezembro 2018). En línea:https://www.eumed.net/rev/turydes/25/accesibilidad-museo.html

Martínez Carrillo, M.J.; Idelhadj, A.; Ouazzani-Touhami, M. (2019): Turismo accesible para todos. Análisis del grado de accesibilidad de los museos de Tétouan (Marruecos), Revista Turydes: $\quad$ Turismo y Desarrollo, $26 \quad$ (junio 2019). $\quad$ En línea:https://www.eumed.net/rev/turydes/26/accesibilidad-museos-tetouan.html

Martínez Carrillo, M.J. y Boujrouf, S. (2020). Turismo accesible para todos, Evaluación del grado de accesibilidad universal de los parques y jardines de Marrakech. Pasos Revista de $\begin{array}{lllll}\text { Turismo } y & \text { Patrimonio } \quad \text { Cultural, } & 18(1), & 57-81 . & \text { En }\end{array}$ linea:https://doi.org/1025145/j.pasos.2020.18.004

Ministère de la culture et de la communication (2007). Culture et Handicap. Guide pratique de l'accessibilité. Paris: Gouberne de France.

Organización de las Naciones Unidas (1975). Declaración de los Derechos de los Impedidos. Nueva York: Organización de las Naciones Unidas-ONU. 
URL:http://www.un.org/spanish/documents/instruments/docs_subj_sp.asp?subj=16

Organización de las Naciones Unidas (1993). Normas Uniformes sobre la Igualdad de Oportunidades para las Personas con Discapacidad. Nueva York: ONU. URL:http://www.un.org/spanish/disabilities/default.asp?id=498

Organizacion de las Naciones Unidas (2006). Convención de los Derechos de las Personas con Discapacidad. Nueva York: ONU.

URL:https://documentsddsny.un.org/doc/UNDOC/GEN/N06/500/82/PDF/N0650082.pdf?OpenElement

Organización Mundial de la Salud (2011). Informe Mundial sobre la Discapacidad 2011 Genève: OMS. URL:http://www.who.int/disabilities/world_report/2011/es/

Organización Mundial de la Salud (2011). Clasificación Internacional del Funcionamiento, de la Discapacidad $y$ de la Salud $(C I F)$. Genève: OMS. URL: http://www.who.int/classifications/icf/en/\#

- Organización Mundial del Turismo (1980). Declaración Mundial de Manila sobre el Turismo Mundial, del 23 de septiembre de 1980, aprobada por la Confederación Mundial de Turismo. Madrid: OMT.

Organización Mundial del Turismo (1999). Código Ético Mundial para el Turismo. Madrid: OMT. URL:http://ethics.unwto.org/es/content/codigo-etico-mundial-para-el-turismo

Organización Mundial del Turismo (2014). Recomendaciones de la OMT por un turismo accesible para Todos. Madrid: URL:http://cf.cdn.unwto.org/sites/all/files/pdf/recomendaciones.pdf

Organización Mundial del Turismo (2014). Manual sobre Turismo Accesible para Todos: Principios, herramientas y buenas prácticas - Módulo I: Turismo Accesible - definición y contexto, OMT: Madrid.

Organización Mundial del Turismo (2015). Manual sobre Turismo Accesible para Todos: Principios, herramientas y buenas prácticas - Módulo II: Cadena de accesibilidad y recomendaciones, OMT: Madrid.

Organización Mundial del Turismo (2015). Manual sobre Turismo Accesible para Todos: Principios, herramientas y buenas prácticas - Módulo IV: Indicadores para el estudio de la accesibilidad en el turismo, OMT, Madrid.

Organización Mundial del Turismo (2016). Día Mundial del Turismo, 2016 Turismo para todos: promover la accesibilidad universal. Buenas prácticas en la cadena de valor del turismo accesible, OMT, Madrid

Organización Mundial del Turismo (2018), Panorama OMT del turismo internacional, Edición 2018. Madrid: UNWTO. URL: https://doi.org/10.18111/9789284419883.

Organización Mundial del Turismo (2016). Barómetro OMT del Turismo Mundial (OMT). URL: http://mkt.unwto.org/barometer

Organización Mundial del Turismo y Organización de los Estados Americanos (2018). El turismo y los Objetivos de Desarrollo Sostenible - Buenas prácticas en las Américas. Madrid: OMT. URL: https://doi.org/10.18111/9789284419937.

Prous Climent, E. y Díaz González, G. (2014). Acceso visible. Un paseo por un museo para todas. Museos.es: Revista de la Subdirección General de Museos Estatales, 9-10, 2013-2014, 
$112-121$

Rodriguez, G (dir) (2014). El sector de la discapacidad: realidad, necesidades y retos futuros. Comité Español de Representantes de Personas con Discapacidad. CERMI y Fundación ONCE, Madrid.

Rovira-Beleta (2003). Libro Blanco de la Accesibilidad. Barcelona: UPC/Mutua Universal.

Rovira-Beleta (2005). La Accesibilidad. Barcelona. URL: www. Rovira-Beleta.com.

Servicio de Información sobre Discapacidad (2005). ¡Pregúntame sobre Accesibilidad y Ayudas Técnicas!. Madrid: Instituto de Biomecánica de Valencia (IBV), Centro Estatal de Autonomía Personal y Ayudas Técnicas (CEAPTA) y Fundación ALIDES (Alianza para el Desarrollo Económico y Social).

Unión Europea (2010) Las personas con discapacidad tienen los mismos derechos. Estrategia Europea sobre Discapacidad 2010-2020. Bruselas: UE.

Zúñiga Robles, Liz (2019). Manual de accesibilidad para museos / elaborada por Liz Zúñiga Robles -- Lima: Museo de Arte de Lima. 